\title{
Protein Profiling of Human Nonpigmented Ciliary Epithelium Cell Secretome: The Differentiation Factors Characterization for Retinal Ganglion Cell line
}

\author{
Ming-Hui Yang, ${ }^{1}$ Raghu R. Krishnamoorthy, ${ }^{2}$ Shiang-Bin Jong, ${ }^{3}$ Pei-Yu Chu, ${ }^{4}$ \\ Yuan-Han Yang, ${ }^{5}$ Wen-Cheng Chen, ${ }^{6}$ Sharon Chia-Ju Chen, ${ }^{3}$ Adnan Dibas, ${ }^{2}$ \\ Thomas Yorio, ${ }^{2}$ Tze-Wen Chung, ${ }^{1}$ and Yu-Chang Tyan ${ }^{3,7,8,9}$ \\ ${ }^{1}$ Department of Chemical and Material Engineering, National Yunlin University of Science and Technology, 123 University Road, \\ Section 3, Douliou, Yunlin 64002, Taiwan \\ ${ }^{2}$ Department of Pharmacology and Neuroscience, University of North Texas Health Science Center, USA \\ ${ }^{3}$ Department of Medical Imaging and Radiological Sciences, Kaohsiung Medical University, 100 Shi-Chuan 1st Road, \\ Kaohsiung 80708, Taiwan \\ ${ }^{4}$ Department of Medical Laboratory Science and Biotechnology, Kaohsiung Medical University, Kaohsiung 80708, Taiwan \\ ${ }^{5}$ Department of Neurology, Kaohsiung Medical University Chung-Ho Memorial Hospital, Kaohsiung 80708, Taiwan \\ ${ }^{6}$ Department of Fiber and Composite Materials, Feng Chia University, Taichung 40724, Taiwan \\ ${ }^{7}$ National Sun Yat-Sen University and Kaohsiung Medical University Joint Research Center, Kaohsiung 80708, Taiwan \\ ${ }^{8}$ Center for Research Resources and Development, Kaohsiung Medical University, Kaohsiung 80708, Taiwan \\ ${ }^{9}$ Center of Excellence for Environmental Medicine, Kaohsiung Medical University, Kaohsiung 80708, Taiwan
}

Correspondence should be addressed to Tze-Wen Chung, twchung@yuntech.edu.tw and Yu-Chang Tyan, yctyan@kmu.edu.tw

Received 5 April 2011; Revised 10 June 2011; Accepted 13 June 2011

Academic Editor: Daniel T. Monaghan

Copyright (C) 2011 Ming-Hui Yang et al. This is an open access article distributed under the Creative Commons Attribution License, which permits unrestricted use, distribution, and reproduction in any medium, provided the original work is properly cited.

The purpose of this paper was to characterize proteins secreted from the human nonpigmented ciliary epithelial (HNPE) cells, which have differentiated a rat retinal ganglion cell line, RGC-5. Undifferentiated RGC-5 cells have been shown to express several marker proteins characteristic of retinal ganglion cells. However, RGC-5 cells do not respond to N-methyl-D aspartate (NMDA), or glutamate. HNPE cells have been shown to secrete numbers of neuropeptides or neuroproteins also found in the aqueous humor, many of which have the ability to influence the activity of neuronal cells. This paper details the profile of HNPE cell-secreted proteins by proteomic approaches. The experimental results revealed the identification of 132 unique proteins from the HNPE cell-conditioned SF-medium. The biological functions of a portion of these identified proteins are involved in cell differentiation. We hypothesized that a differentiation system of HNPE cell-conditioned SF-medium with RGC-5 cells can induce a differentiated phenotype in RGC-5 cells, with functional characteristics that more closely resemble primary cultures of rat retinal ganglion cells. These proteins may replace harsh chemicals, which are currently used to induce cell differentiation.

\section{Introduction}

Primary open angle glaucoma (POAG), a leading cause of irreversible blindness worldwide, is an optic neuropathy characterized by the gradual and progressive loss of retinal ganglion cells (RGCs), optic nerve degeneration, and excavation of the optic disks [1-4]. The hypothesis has been that larger RGCs were selectively lost in the early stage of glaucoma [5]. Although the mechanisms of optic nerve damage in glaucoma have not been completely determined, it appears that the optic nerve head is a major site of damage [6].

RGCs can generate action potentials that travel along the optic fibers [7]. In general, RGCs are a mixture of more than 20 cell subtypes. They have energy-dependent axonal 
transport functions-orthograde and retrograde transports [8]. These terminal projection areas are in the lateral geniculate body. RGCs can be subdivided by their morphology and physiology, but they are usually discussed without classifications.

The in vitro study of the physiology and pathophysiology of RGCs has been limited to primary cultures. Previous studies have characterized a transformed rat retinal ganglion cellline (RGC-5), which expresses many neuronal cell markers, including Thy-1, a cell surface glycoprotein found predominantly in the retinal ganglion cells $[6,9,10]$, and Brn3C, a POU domain transcription factor expressed exclusively in the retinal ganglion cells [11]. RGC-5 cells also express receptors of N-methyl-D aspartate (NMDA), GABA-B, and neurotrophin [6]. However, unlike primary RGCs, these cells were not sensitive to glutamate excitotoxicity in their undifferentiated state. RGC-5 cells pretreated with succinyl concanavalin-A (sCon A) were sensitive to $500 \mu \mathrm{M}$ glutamate [12]. Lacking glutamate sensitivity causes the difficulties of using the RGC-5 cells in experiments involving glutamate.

Ocular ciliary epithelium cells have been shown to be involved in the synthesis and secretion of various proteins found in aqueous humor [13]. Several proteins, including neuropeptides and their processing enzymes, synthesized and secreted by a human nonpigmented ciliary epithelial (HNPE) cell-line, have been evaluated [14], and it is suggested that these secreted proteins can act in an autocrine or paracrine manner to affect ciliary epithelial functions and other target ocular cells, such as the trabecular meshwork [13]. Because of the neuroendocrine properties of the ciliary epithelium cells, the ability to confer differentiated neuroendocrine phenotypes and the physical locations of these ciliary epithelium cells and RGCs [15], we hypothesized that factors secreted by these HNPE cells may induce the RGC-5 cells to differentiate, and possibly induce glutamate and NMDA sensitivities.

Proteomic analysis, including identification and characterization, is a powerful tool for determination of biological roles and functions of individual proteins. In the present report, we have utilized a system involving HNPE and RGC5 cells, and this system may result in the morphological and functional differentiation of RGC-5 cells. Although the origin of RGC-5 has been still in question, the expression of neuronal markers was validated [16]. Proteomic approaches have been applied to establish a map of expressed proteins for the characteristics of HNPE cells.

\section{Materials and Methods}

2.1. Cell Culture. The human non-pigmented ciliary epithelium cells (HNPE) were SV-40 transformed and were a gift from Dr. Miguel Coca-Prados (Yale University). HNPE were maintained at $37^{\circ} \mathrm{C}$ and $5 \% \mathrm{CO}_{2}$ in Dulbecco's modified Eagle's medium (DMEM, Gibco, Grand Island, NY, USA) supplemented with $10 \%$ fetal bovine serum (FBS, Hyclone Laboratories, Logan, UT), 1\% penicillin/streptomycin (Gibco, Grand Island, NY, USA) and $44 \mathrm{mM} \mathrm{NaHCO}_{3}$. After three days, the cells were washed with phosphate buffered saline (PBS) and the medium was replaced by serum-free (SF) DMEM for $12 \mathrm{~h}$.

The HNPE cell conditioned SF-medium was filtered by $0.22 \mu \mathrm{m}$ filter and diluted 25 times with autoclaved Milli-Q grade water (Millipore Co., Inc.). For each $5 \mathrm{kD}$ cutoff centrifugal tube (Amicon Ultra-15, Millipore Co., Inc.), a $15 \mathrm{~mL}$ diluted sample was loaded. Following centrifugation at $5000 \times \mathrm{g}$ for $20 \mathrm{~min}$, the sample in the filter unit was collected. The protein concentration of the HNPE cell conditioned SF-medium was measured by the Bio-Rad Bradford total protein assay kit (Bio-Rad Laboratories, Inc.).

RGC-5 cells, a secondary cell culture, were transformed rat retinal ganglion cells developed and obtained from Dr. Agarwal (University of North Texas Health Science Center). RGC-5 cells were maintained in low glucose DMEM in T150 culture flasks supplemented with $44 \mathrm{mM} \mathrm{NaHCO}_{3}, 10 \%$ FBS, and $1 \%$ penicillin/streptomycin (Gibco). Differentiated RGC- 5 cells were obtained by using 50\% HNPE cell conditioned SF-medium and 50\% fresh DMEM (containing 10\% FBS). HNPE conditioned medium, which consisted of low glucose DMEM, was incubated with human non-pigmented ciliary epithelial cells (HNPE).

2.2. Immunocytochemistry. RGCs were grown on glass coverslips for 1-2 days prior to experimentation. Coverslips were rinsed with PBS three times and then were fixed in $4 \%$ paraformaldehyde for $30 \mathrm{~min}$. These cells were washed with PBS before being permeabilized in $0.1 \%$ Triton X-100 for $15 \mathrm{~min}$, washed with PBS, and blocked with 5\% bovine serum albumin for $60 \mathrm{~min}$. After rinsing with PBS, the cells were incubated with a mixture of Thy-1 (monoclonal antibodies, Chemicon, Temecula, CA, 1:200) and Brn3C (polyclonal antibodies, Convance Inc, Princeton, NJ, $1: 1000$ ) for $1.5 \mathrm{~h}$ at room temperature and subsequently incubated with a combination of secondary antibodies. After PBS rinses, these cells were incubated for $10 \mathrm{~min}$ in the dark with $300 \mathrm{nM}$ DAPI to stain nuclear regions. Cover-slides were mounted on glass slides in antifade medium (FluorSave; Calbiochem, La Jolla, CA) and allowed to dry for $20 \mathrm{~min}$ in the dark. Cells were visualized and images were taken using a Zeiss LSM-410 Confocal Scanning Laser Microscope System. Controls were performed by omitting primary antibodies.

2.3. ID SDS-PAGE. HNPE cell-secreted proteins were separated under denaturing conditions in a $4-12 \%$ polyacrylamide gel. The HNPE cell conditioned SF-medium was resuspended in the sample buffer (Invitrogen NuPAGE SDS sample buffer), heated at $80^{\circ} \mathrm{C}$ for $10 \mathrm{~min}$ and then stored on ice. Each well was loaded with $5 \mu \mathrm{g}$ of sample solution. The SDS-PAGE gel was run in a Bio-Rad protean II xi cell (Richmond CA, USA) at $200 \mathrm{~V}$ for $1 \mathrm{~h}$. After completion of electrophoresis, the protein bands in the gel were visualized by silver staining and image acquired using an image scanner (Amersham Biosciences, Uppsala, Sweden), which is operated by the software LabScan 5.00 (Amersham Biosciences).

2.4. Silver Staining. The gels were fixed in an aqueous solution having $40 \%$ ethanol and $10 \%$ acetic acid overnight, 
and then incubated in a buffer solution containing 30\% ethanol, $6.8 \% \mathrm{w} / \mathrm{v}$ sodium acetate, and $0.312 \% \mathrm{w} / \mathrm{v}$ sodium thiosulfate for $30 \mathrm{~min}$. After rinsing three times for $5 \mathrm{~min}$ each, the gels were stained in a $0.25 \% \mathrm{w} / \mathrm{v}$ silver nitrate solution containing $0.02 \%$ formaldehyde for $30 \mathrm{~min}$. The development was performed for $10 \mathrm{~min}$ in a solution consisting of $2.5 \%$ sodium carbonate and $0.01 \%$ formaldehyde. An acetic acid solution (5\% v/v) was used to stop the development, and the stained gels were then rinsed three times for 5 min each.

2.5. Protein Identification by Nano-HPLC-ESI-MS/MS. The protein bands were excised manually and digested using sequence grade trypsin (V511A, Promega, USA). The protein samples were reduced, alkylated, and then digested with trypsin using standard protocols $[17,18]$.

Reverse phase nano-high performance liquid chromatography electrospray ionization tandem mass spectrometry (RP-nano-HPLC-ESI-MS/MS) was used to identify the selected protein bands separated on the SDS-PAGE. The peptides obtained from the tryptic in-gel digestion were analyzed using a nano-HPLC system (LC Packings, Netherlands) coupled to an ion trap mass spectrometer (LCQ Deca XP Plus, ThermoFinnigan, San Jose, CA, USA) equipped with an electrospray ionization source. A linear acetonitrile gradient from $100 \%$ buffer A (5\% acetonitrile $/ 0.1 \%$ formic acid) to $60 \%$ buffer B ( $80 \%$ acetonitrile $/ 0.1 \%$ formic acid) was used at a flow rate of approximately $200 \mathrm{~nL} / \mathrm{min}$ for $70 \mathrm{~min}$. The separation was performed on a C18 microcapillary column (Zorbax 300SB-C18, $3.5 \mu \mathrm{m}, 75 \mu \mathrm{m}$ I.D. $\times 150 \mathrm{~mm}$, Agilent, Germany). Peptides eluted from the microcapillary column were electrosprayed into the nano-HPLC-ESI-MS/MS with the application of a distal $1.3 \mathrm{kV}$ with heated capillary at the temperature of $200^{\circ} \mathrm{C}$. Each cycle of one full scan mass spectrum (m/z 450-2000) was followed by three datadependent tandem mass spectra with the collision energy was set at $35 \%$.

2.6. Database Search. For protein identification, Mascot software (Version 2.2.1, Matrix Science, London, UK) was used to search the human protein sequence database (SwissProt, Release 52.0 of 22-Feb-08). For proteolytic cleavages, only tryptic cleavage was allowed, and the number of maximal internal (missed) cleavage sites was set to 2 . Variable modifications of cysteine with carboxyamidomethylation, methionine with oxidation, and asparagine/glutamine with deamidation were allowed. The mass tolerances of the precursor peptide ion and fragment ion were set to $1 \mathrm{Da}$. Positive protein identifications were defined if the Mowse scores of greater than 50 were considered significant $(P<0.05)$. Proteins were initially annotated by similar searches using UniProtKB/Swiss-Prot databases (Last modified September 22, 2009) [19-21].

\section{Results and Discussion}

Cell secretome (cell-conditional medium) studies can make major contributions in understand biomarker discovery and cell pathophysiological mechanisms. It is composed of proteins that are found in the extracellular growth medium. The cell secretome consists of proteins that are secreted, shed from the cell surface and intracellular proteins released into the supernatant due to cell lysis, apoptosis, and necrosis [22, 23]. The secretome which consists of proteins or peptides secreted from cells into the extracellular medium represents the major class of molecules involved in the intercellular communication in multicellular organisms. It constitutes an important class of proteins that control and regulate a multitude of biological and physiological processes and indicates a clinically relevant source for biomarker and therapeutic target discoveries [24].

Thus, secreted proteins constitute an important category of active molecules that play crucial roles in a number of physiological and pathological processes and may reflect a broad variety of pathological conditions and thus represent a rich source of biomarkers. Proteomic characterization of proteins for identification of specific biomarkers provides a powerful tool to gain deep insights into disease mechanisms in which proteins play major roles. In this study, we have used gel electrophoresis associated with mass spectrometry for identification of the proteome and secretome of HNPE cell conditioned SF-medium samples.

3.1. RGC-5 Cell Differentiation. The differentiation system consisted of RGC-5 cells on coverslips inside 6-well plates, which were exposed to the conditioned medium from HNPE cells. RGC-5 cells proliferated rapidly with a doubling time of less than a day. Decreasing the percentage of serum in the medium may slow down proliferation. The control RGC-5 cells were heterogeneous in shape. Morphological changes of RGC-5 cells were induced by HNPE cell conditioned SF-medium (Figure 1) and caused the shrinkage of the cell body with elongated neurite outgrowth (Figure 1(b)), which allows comparison with undifferentiated RGC-5 cells (Figure 1(a)). The overall morphology of RGC-5 cells after the treatment was similar to those seen in primary cultures of rat retinal ganglion cells [25]. Moreover, the morphology of RGC- 5 cells differentiated by our method was similar to the ones induced by a broad-spectrum protein kinase inhibitor staurosporine [26]. Nevertheless, Frassetto and coworkers did not conclude this to be the possible differentiation mechanism. This secretome map is a preliminary study to unveil the mechanism since the differentiation is probably the consequence of the action of several proteins and/or enzymes. It was also noted that the differentiation treatment led to decreased culture density compared with the control cells. This finding is consistent with the study from Wood et al. [27]. For subsequent studies, the conditioned medium from confluent flasks containing HNPE cells was used and found to be equally effective in promoting differentiation of RGC-5 cells.

Thy-1 expression in undifferentiated RGC-5 cells was used as a marker to identify retinal ganglion cells [28]. After treatment with HNPE cell conditioned SF-medium, RGC-5 cells have an enhanced Thy-1 expression, compared to the undifferentiated cells (Figure 2). In the retina, the 


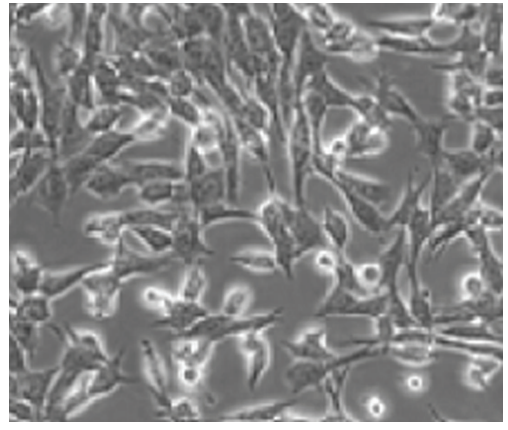

(a)

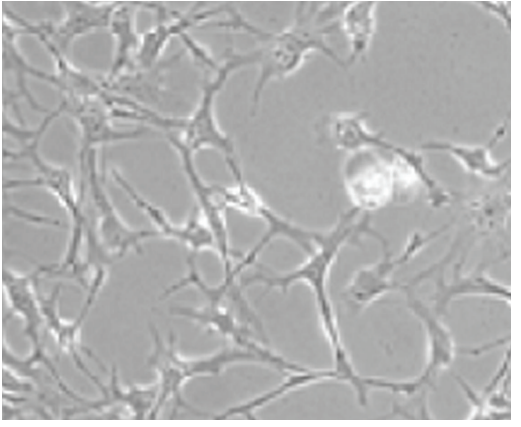

(b)

FIGURE 1: Morphological changes in RGC-5 cells after treatment with HNPE conditioned SF-medium (40x) (a) before, and (b) after. The RGC-5 cells treated with HNPE conditioned SF-medium induced morphological changes, including longer axons and more neurite outgrowth (Figure 1(b)), compared to RGC-5 cells without treatment (Figure 1(a)).

DIC

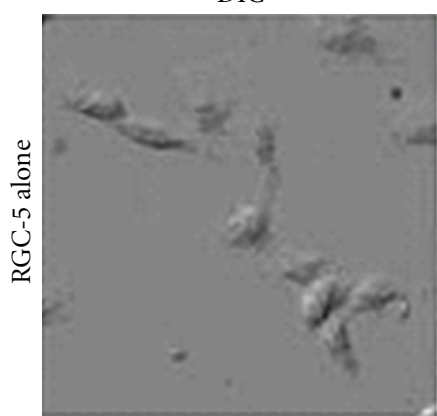

(a)

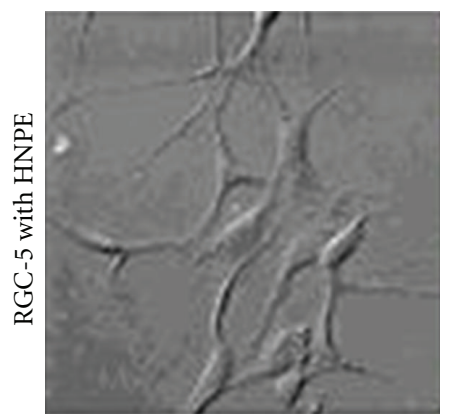

(c)
Thy-1
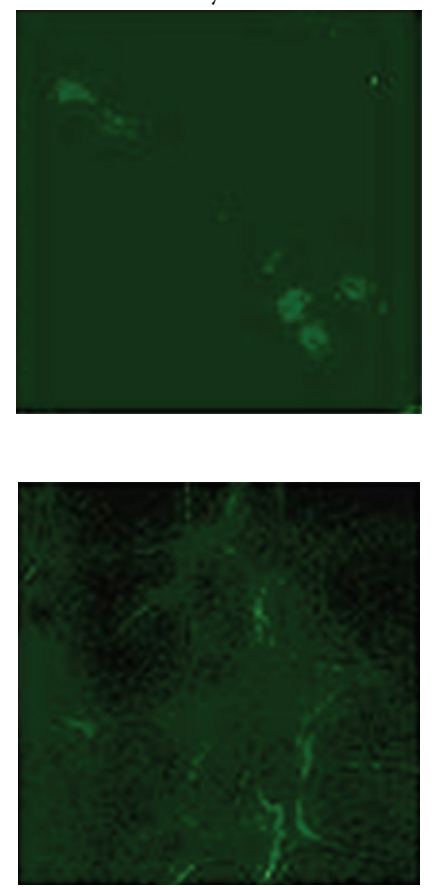

DIC

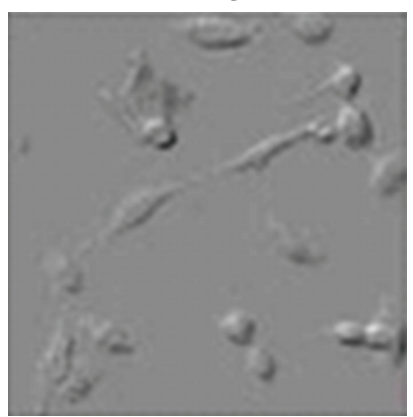

(b)

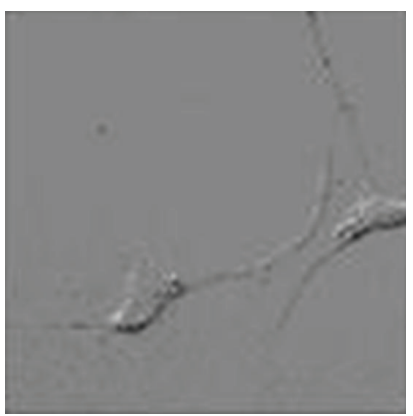

(d)
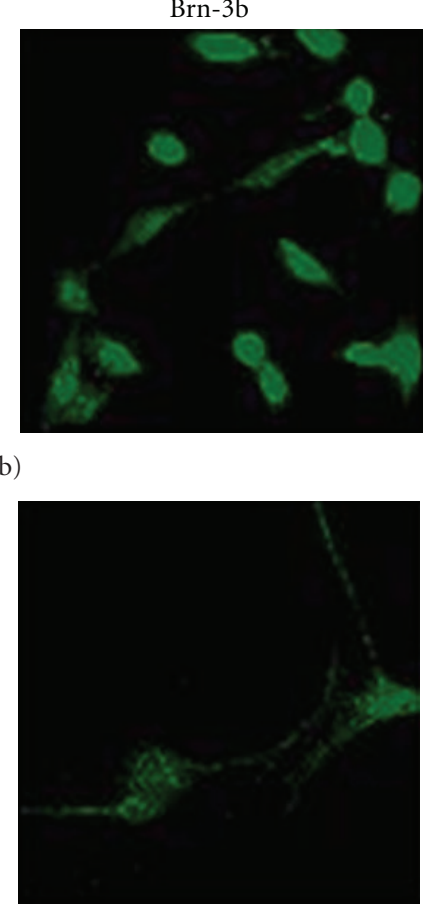

FIGURE 2: Immunocytochemical analysis of Thy-1 and Brn-3b expression in RGC-5 cells differentiated by treatment with HNPE cell conditioned SF-medium. Staining with antibodies to the cell surface glycoprotein, Thy-1, have been commonly used as a marker to identify retinal ganglion cells. After cultivation with HNPE conditioned medium, RGC-5 cells have an enhanced Thy-1 expression, compared to the undifferentiated cells. RGC-5 cells without cultivation with HNPE conditioned medium express Brn-3b in a different pattern compared with treated RGC-5 cells. Specifically, Brn-3b has a nuclear localization in RGC-5 cells without cultivation with HNPE conditioned medium; however, upon treatment, RGC-5 cells express Brn-3b in a more punctate cytosolic manner.

class IV POU domain transcription factor, Brn-3b, was expressed almost exclusively in subpopulations of ganglion cells and used to identify RGCs [29]. Brn-3b was regarded as a marker for differentiation of RGCs, since Brn-3 factors were not necessary for the initial specification of sensory neurons, but were essential for their normal differentiation and survival [30]. Specifically, Brn-3b was localized in the nuclear in RGC-5 cells; however, upon treatment with HNPE cell conditioned SF-medium, RGC-5 cells express Brn-3b in a more punctate cytosolic manner (Figure 2).

3.2. Proteome Analysis. The SDS-PAGE followed by silver staining resolved the protein bands from HNPE cell conditioned SF-medium. Figure 3 shows the silver-stained 1D SDS-PAGE of secreted proteins from HNPE cells. Five micrograms of secreted protein was loaded on a gel for 


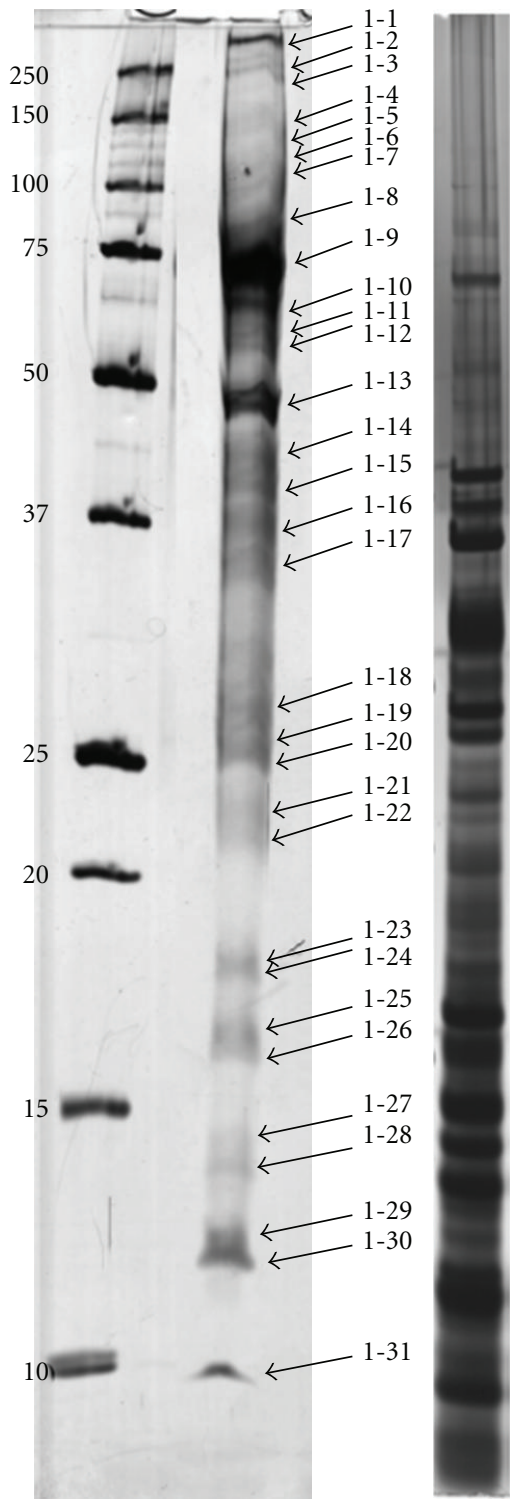

FIGURE 3: 1D SDS-PAGE image of HNPE conditioned SF-medium ( $5 \mu \mathrm{g} /$ well, silver stained, left-hand side: molecular weight marker, $\mathrm{kDa})$. The gel bands on the middle lane with serial numbers were analyzed by nano-HPLC-ESI-MS/MS. In the 30 bands, 132 proteins were identified. The gel bands on the right-hand side were the cell lysised proteins.

visualization, and more than 30 protein bands were detected in the HNPE conditioned SF-medium using the image analysis software. To identify the proteins, the position of the 1D SDS-PAGE lane was excised from the gel, washed to remove the stain, and subjected to tryptic digestion. The resulting peptides were characterized by nano-HPLCMS/MS for protein identification. When a protein was identified by three or more unique peptides possessing MASCOT scores, no visual assessment of spectra was conducted and the protein was considered present in the sample.

In this study, all MS/MS spectra were manually confirmed (even if the above criteria were passed) by the visual assessment for their overall quality. In addition, the criteria for manual validation reported by Jaffe et al., which requires a readily observable series of at least four $y$-ions, was used [31]. Thus, the criteria should be enough for the validation of the identified proteins. By using this strategy, 132 unique proteins with at least three unique peptide sequences matched were identified, and a summary of the protein identifications achieved is listed in Table 1.

In this study, 47 proteins $(35.6 \%)$ were known to be present in cytoplasm. Twenty-two proteins (16.7\%) were known to be secreted into the extracellular space. Twenty-five proteins $(18.9 \%)$ were known to be nuclear proteins. Eleven proteins $(8.3 \%)$ were known to be membrane proteins. Ten proteins $(7.6 \%)$ were known to be cytosol proteins. A few mitochondrial, endoplasmic reticulum, intracellular, cytoskeleton, and golgi apparatus proteins were also identified. A considerable portion of the identified proteins $(6 \%$, 8 proteins) has not been reported for their synthesized locations. Some proteins were described as found in different subcellular locations, which explains the total sum being substantially larger than $100 \%$.

Some identified proteins in the distribution of cellular location were not secreted proteins, but they were still present in the secreted medium. To clarify the puzzle, a cell viability test was applied. The survival rate of HNPE cells was determined by the dimethylthiazol-diphenyltetrazolium bromide (MTT) assay, which was about 97\%. Thus, those identified proteins were not corresponding to released proteins from dead cells. Also, according the protein profiles in Figure 3, the protein patterns obtained from secreted medium and cell lysate were very different. As a result, these proteins identified in this study can be considered as secreted proteins, which may have been synthesized inside the cells and transferred out.

Based on the functional categories in the Swiss-Prot and TrEMBL protein database, the identified proteins were classified into several groups. The Swiss-Prot identifiers could be employed for linkages of proteins to defined vocabulary of terms describing the cellular components, biological processes, and molecular functions of known gene ontology (GO). Gene Ontology Consortium provides annotations of each protein and its structure, which allowed us to organize selected proteins into biologically relevant groups. These groupings can be utilized as the basis for identifying biological information showing correlated protein changes $[20,32]$. Such protein functions were listed in Table 2.

In this study, some of the proteins secreted by HNPE cells, which were confirmed by the Western blotting method, may be candidate factors responsible for promoting differentiation of RGC-5 cells including thrombospondin-1, 2, 3 precursor (1-2, 1-3, 1-13), galectin-3-binding protein (1$5 \sim 1-7$ ), neurogenic locus notch homolog protein 3 (Notch$3,1-11$ ), follistatin-related protein 1 precursor (1-11), sPARC precursor (1-14), peroxiredoxin-1 (1-21, 1-22), cofilin 1 (1$24,1-27)$, profilin $1(1-27,1-28)$, galectin-1 (1-28), and myotrophin (1-30). Cell differentiation is directed by a variety of intra- and extracellular events including signals generated by extracellular matrix (ECM) components, which mediate adhesive cell-to-cell interactions and trigger a cascade of post-receptor intracellular signaling pathways. The 


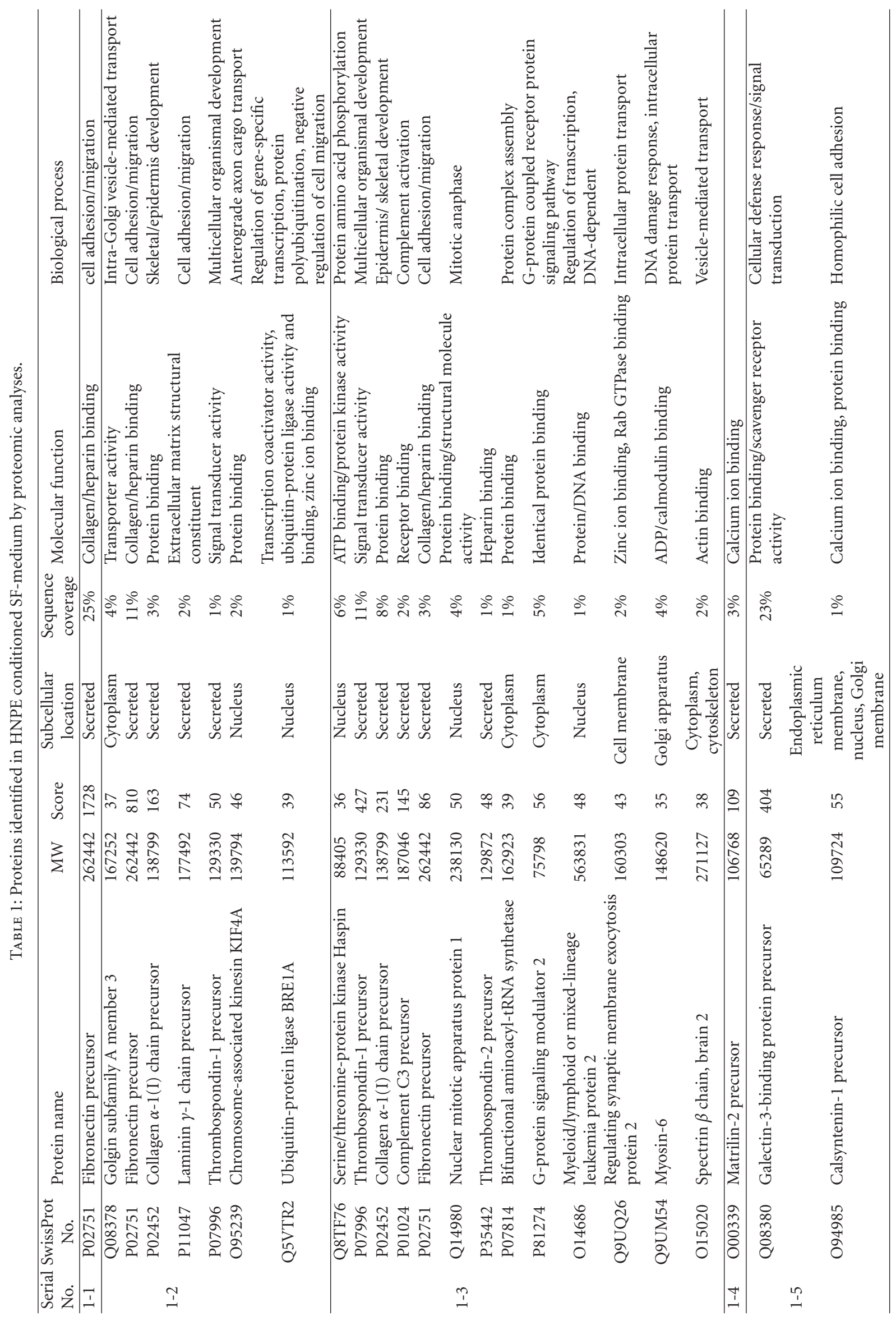




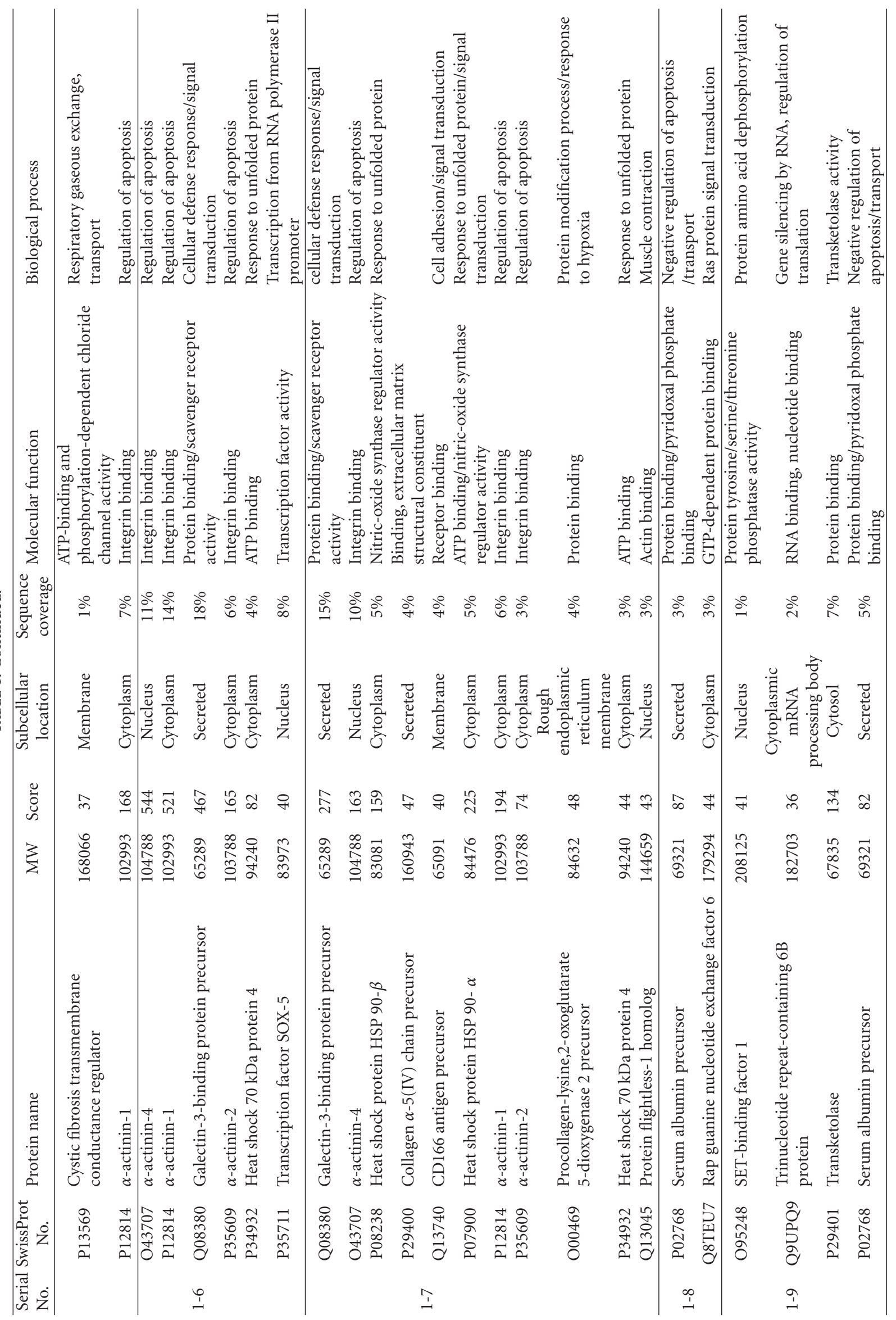




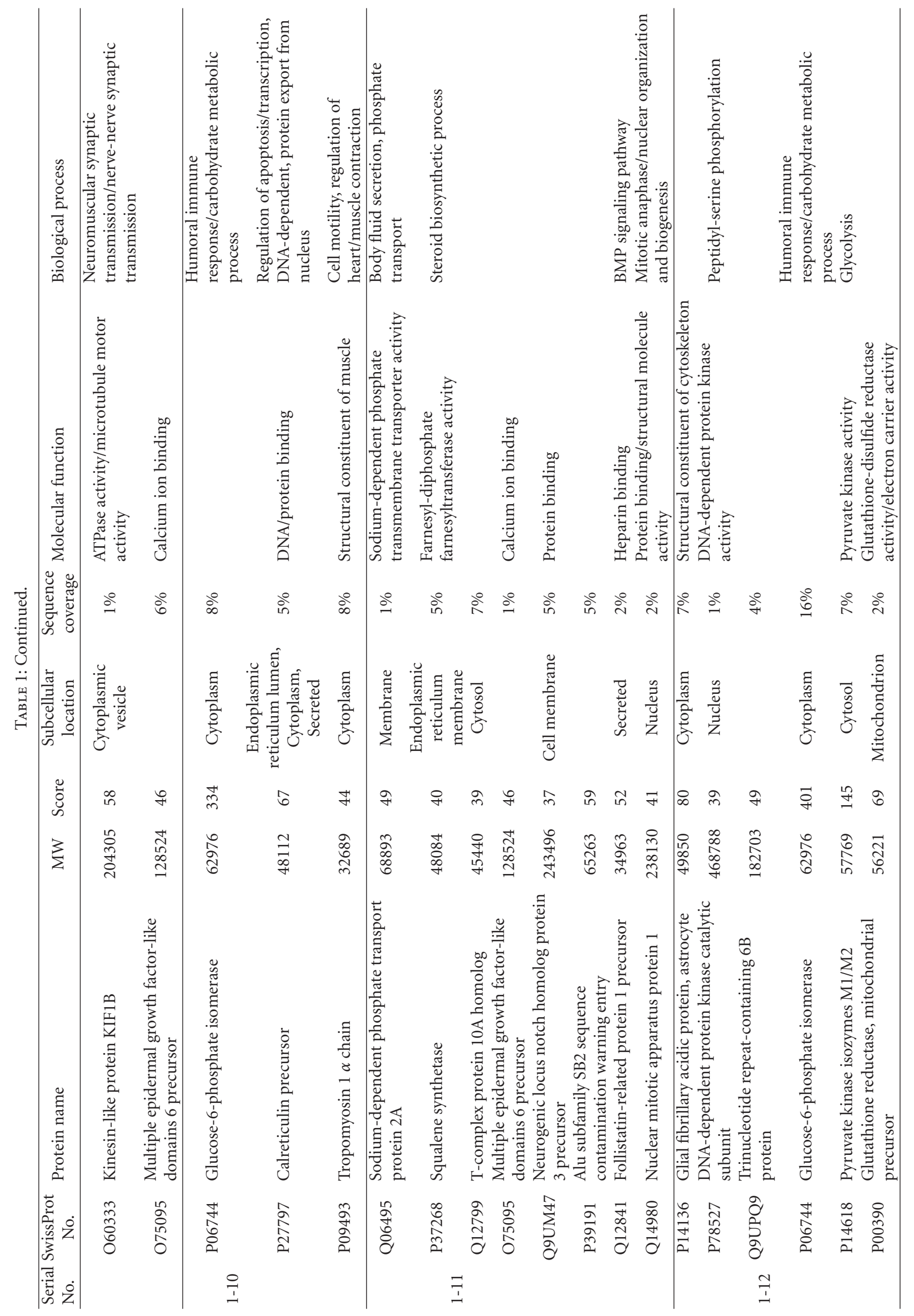




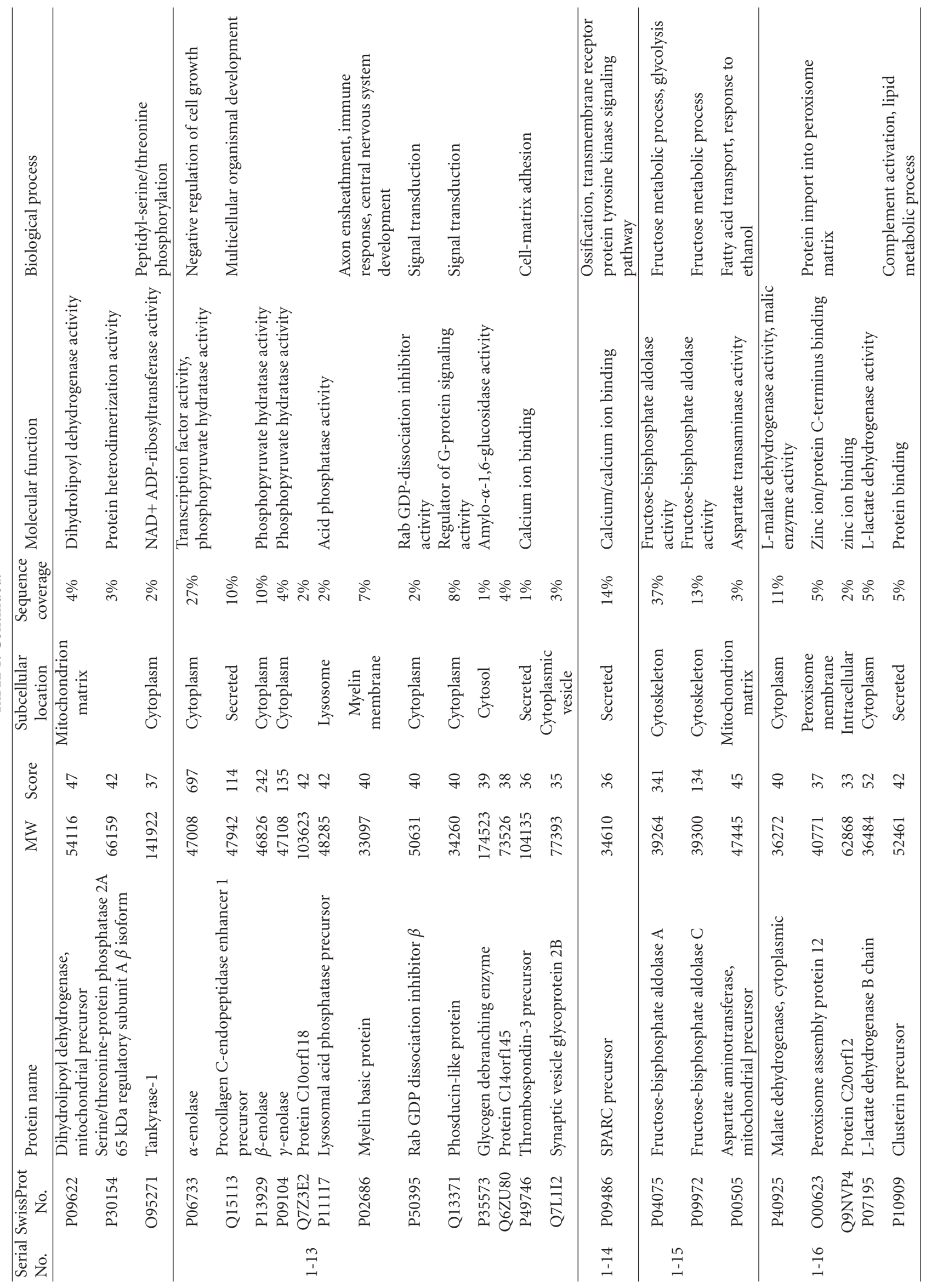




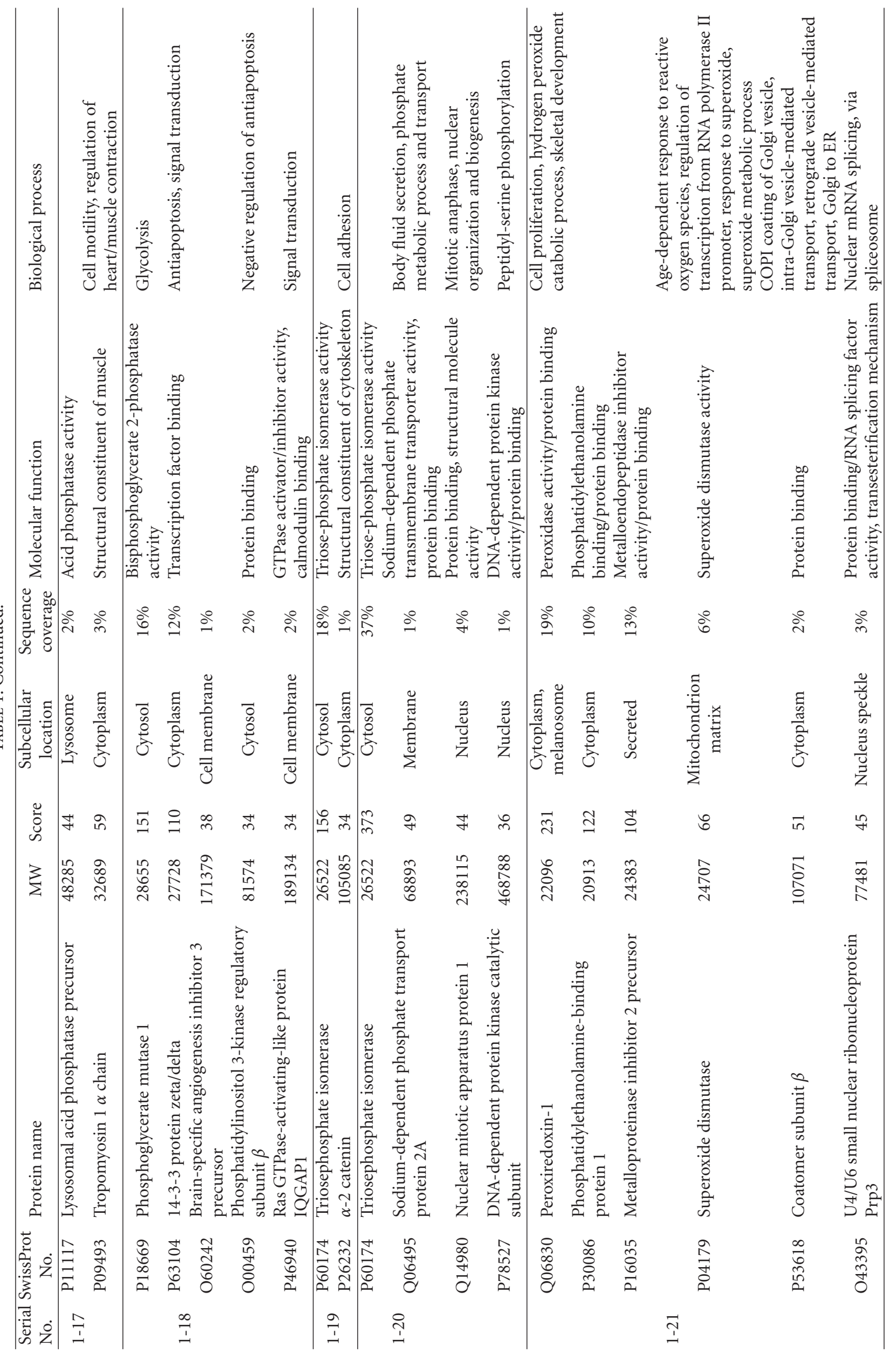




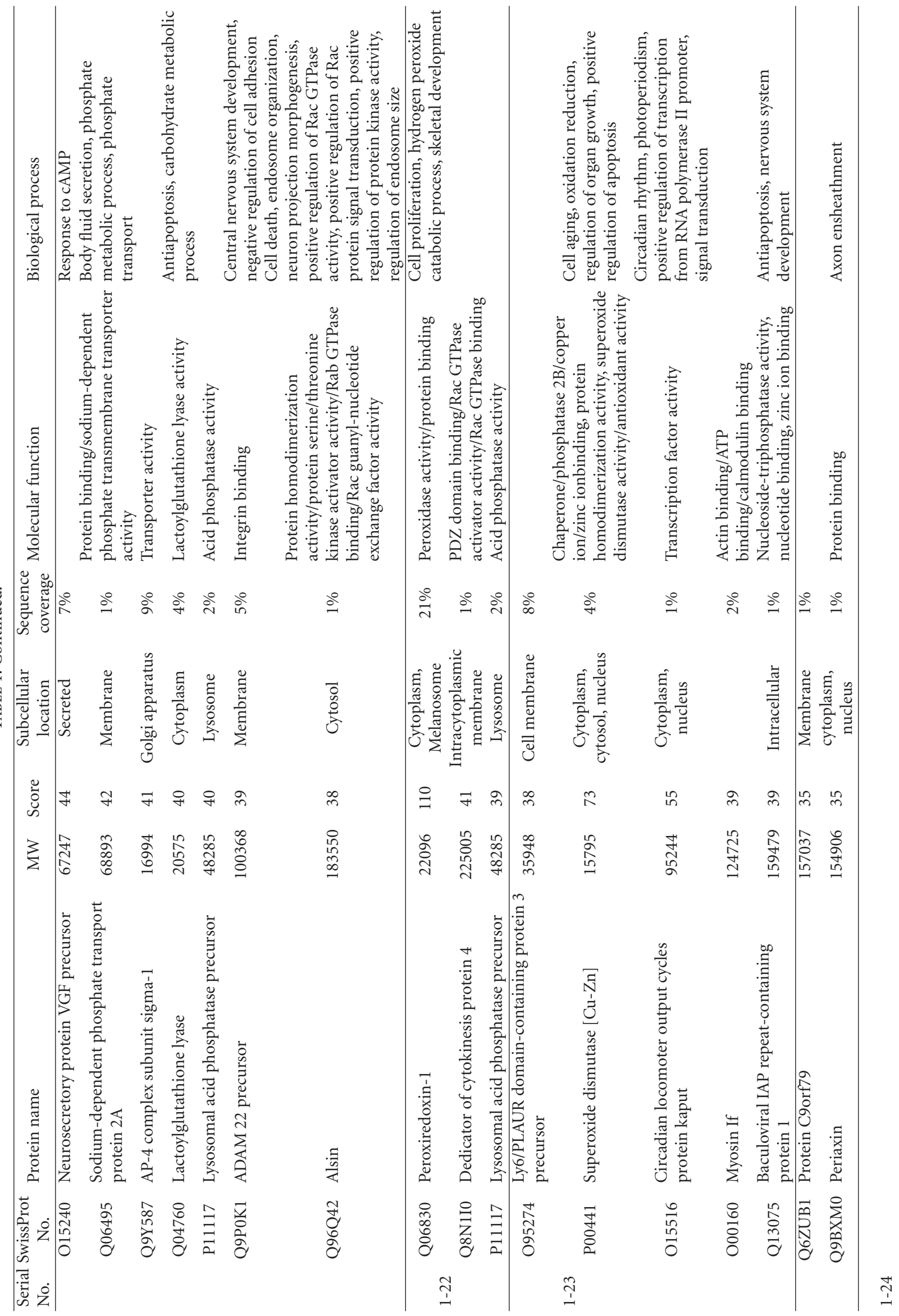




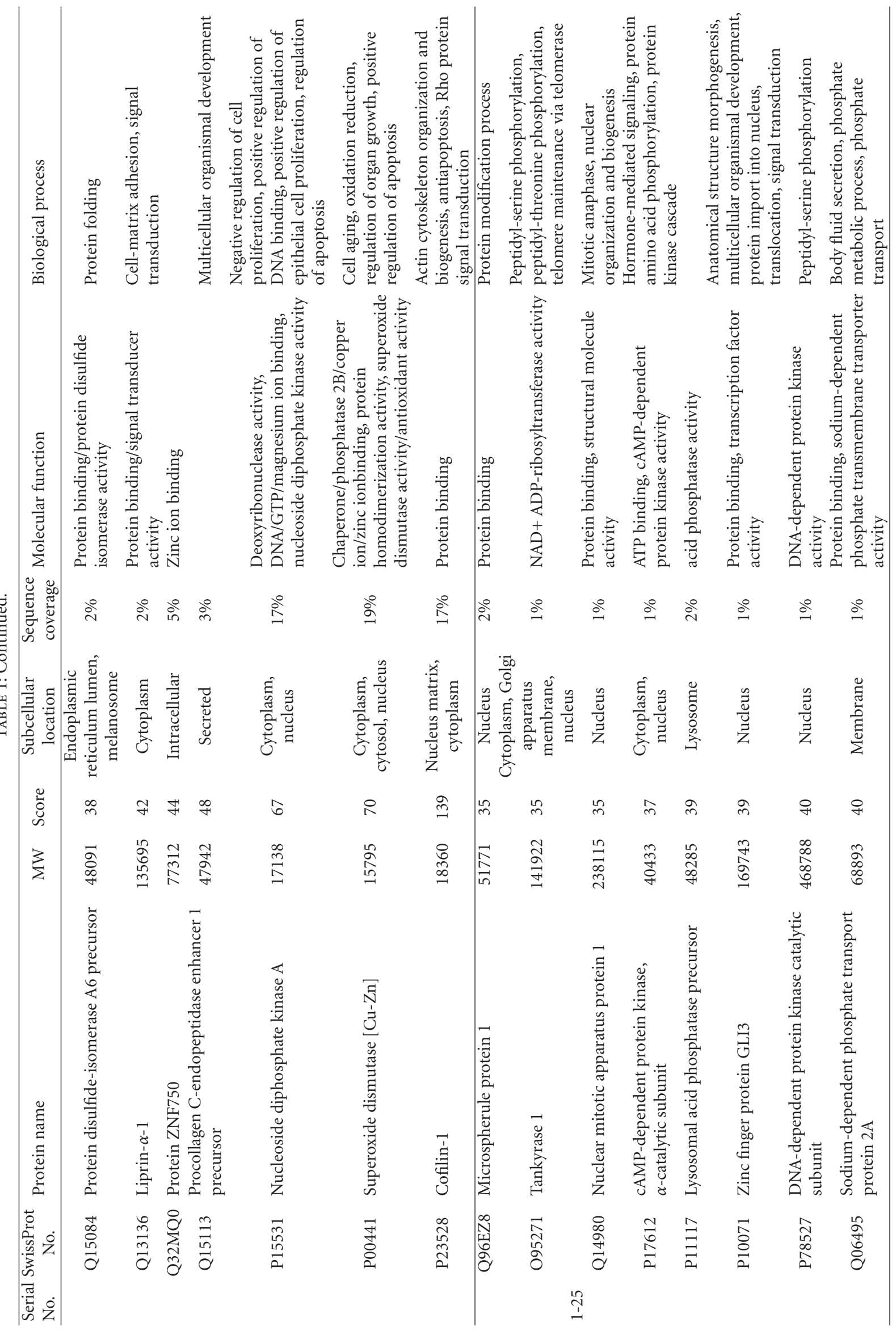




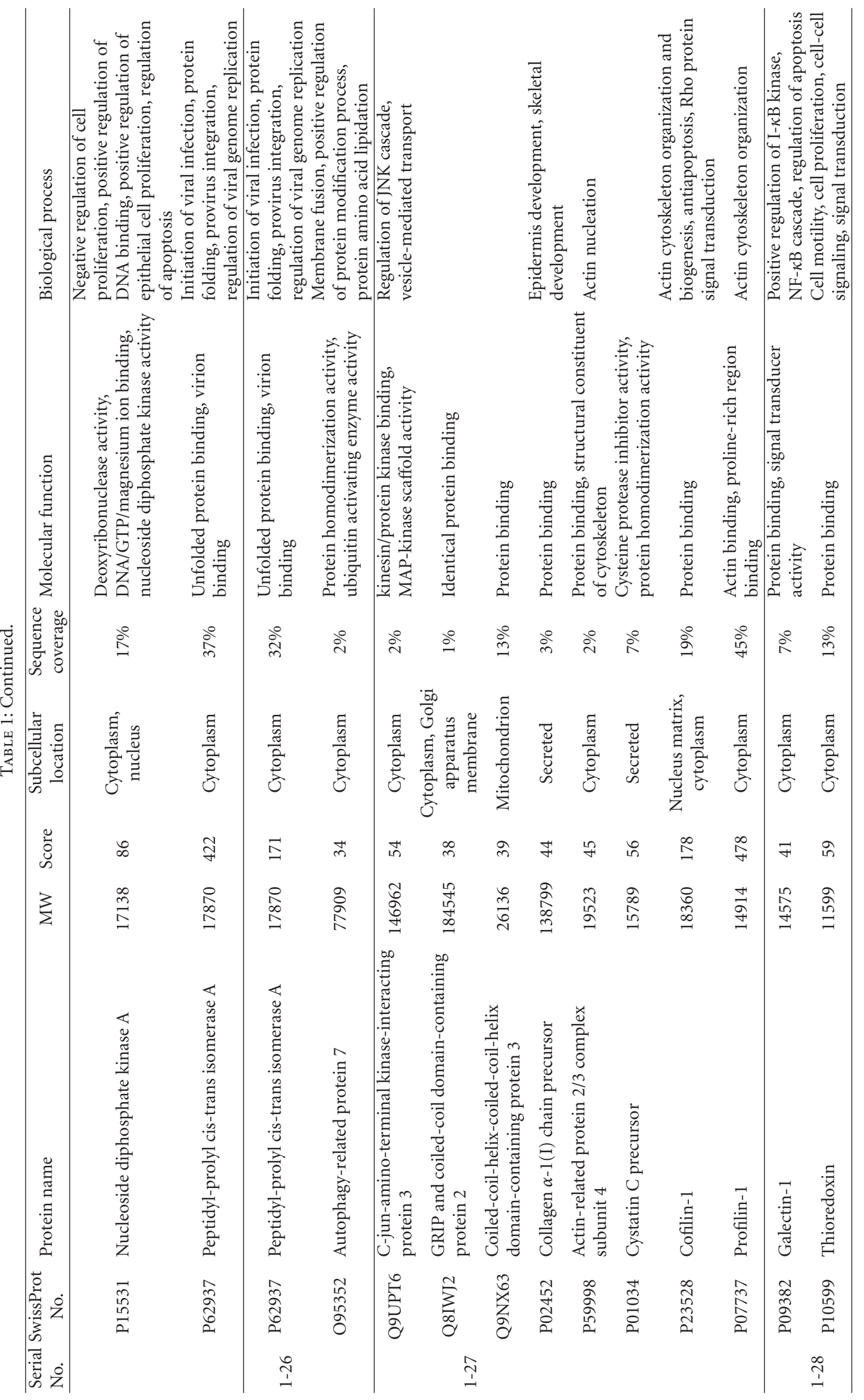




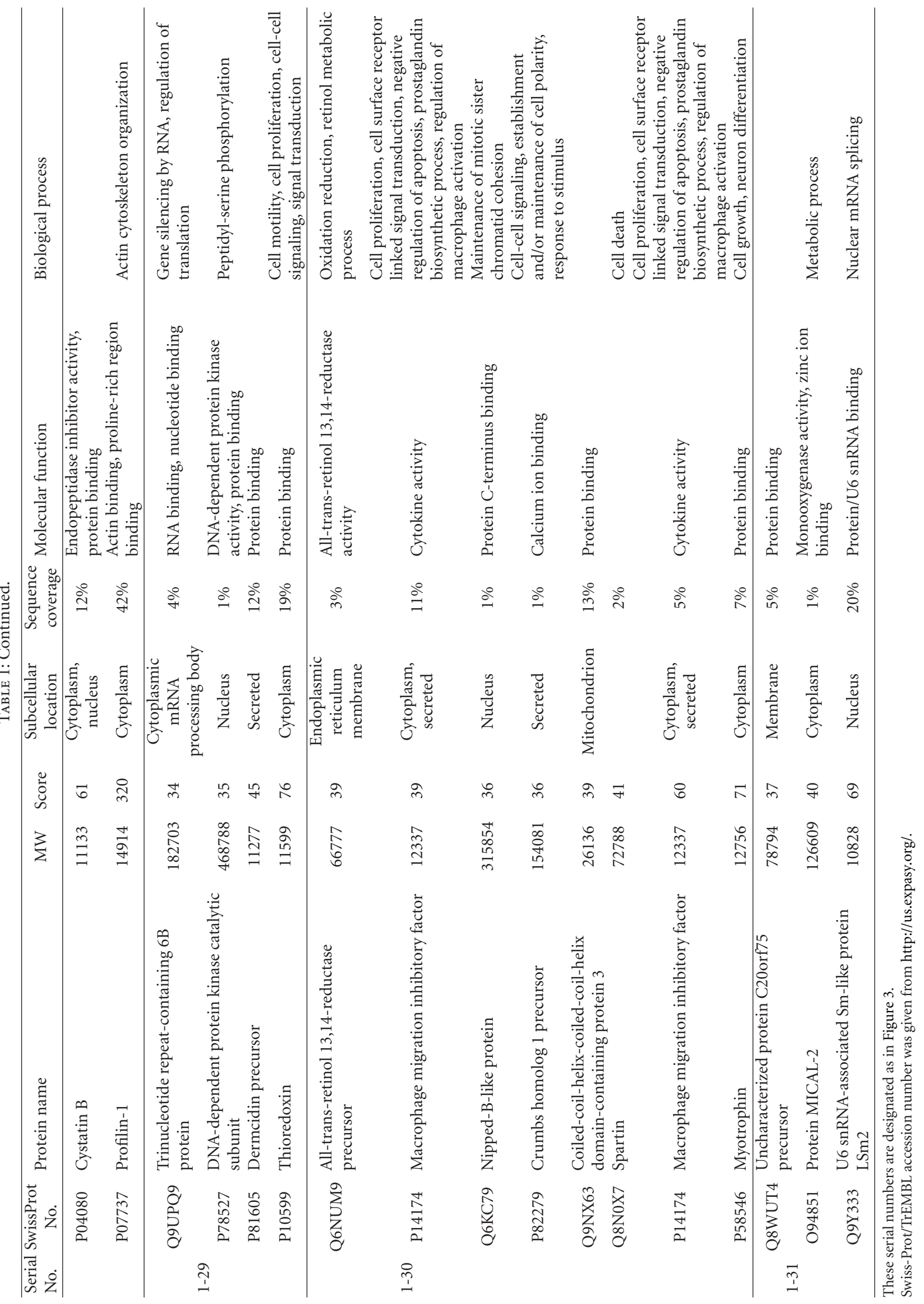




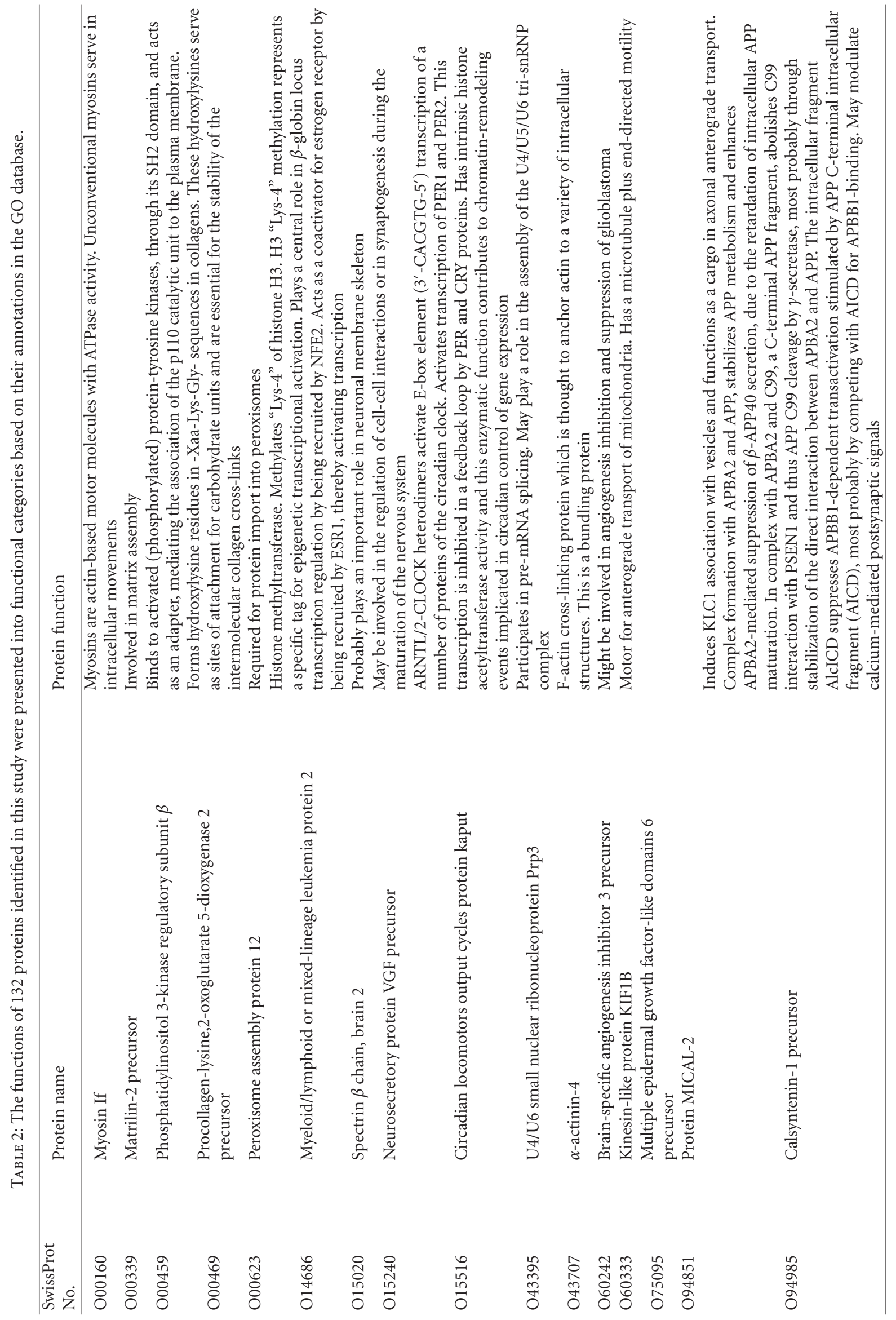




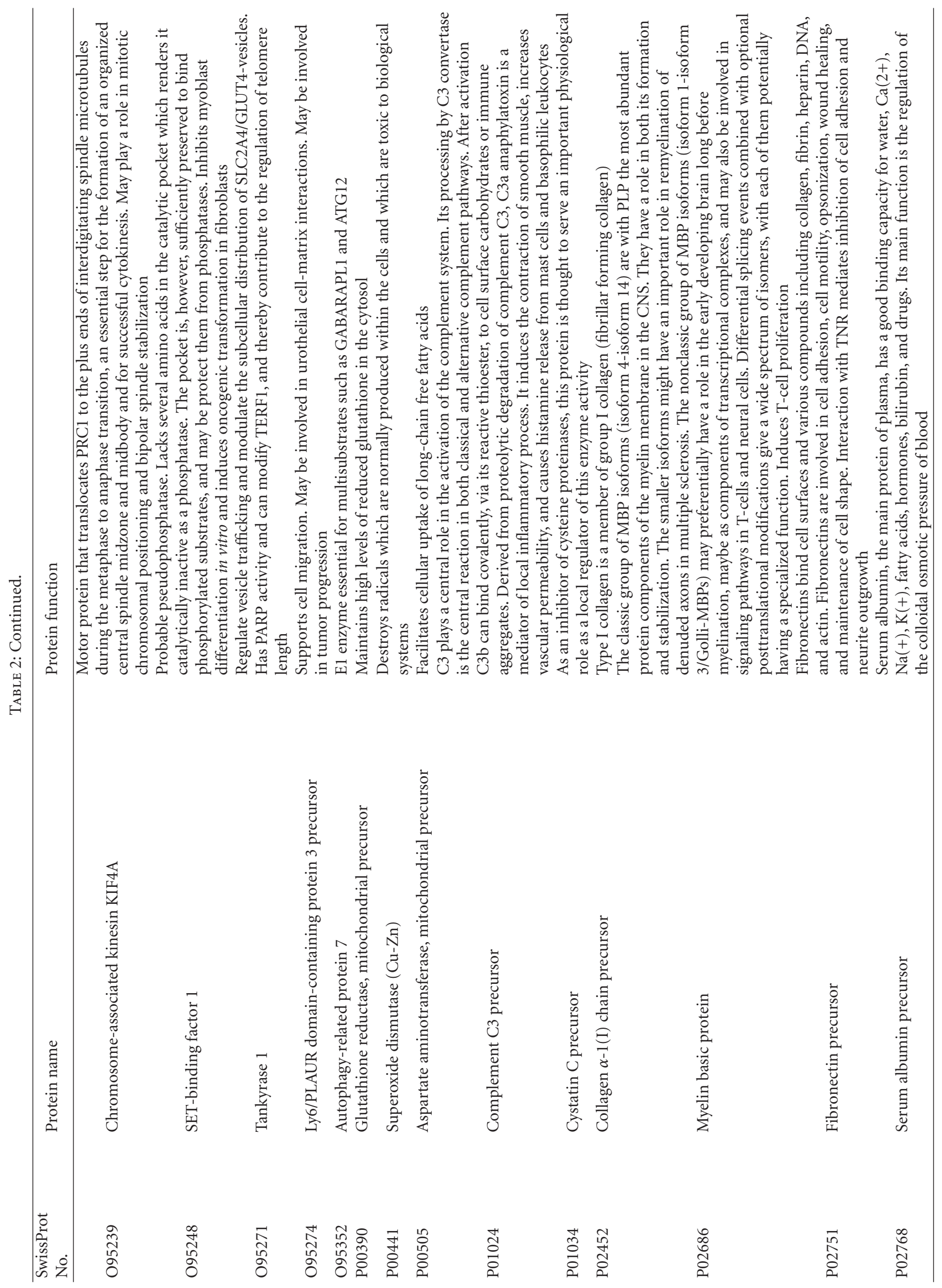




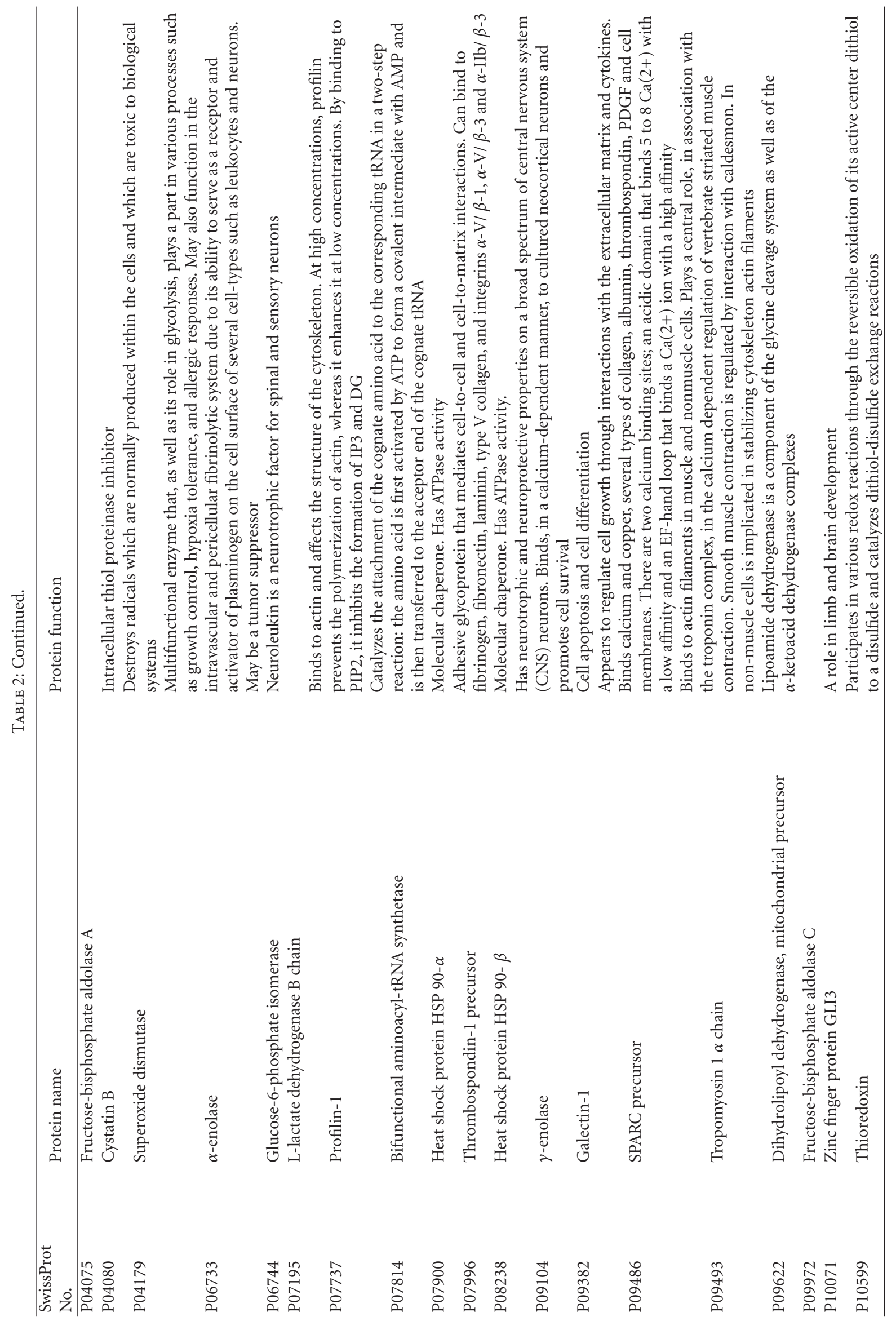




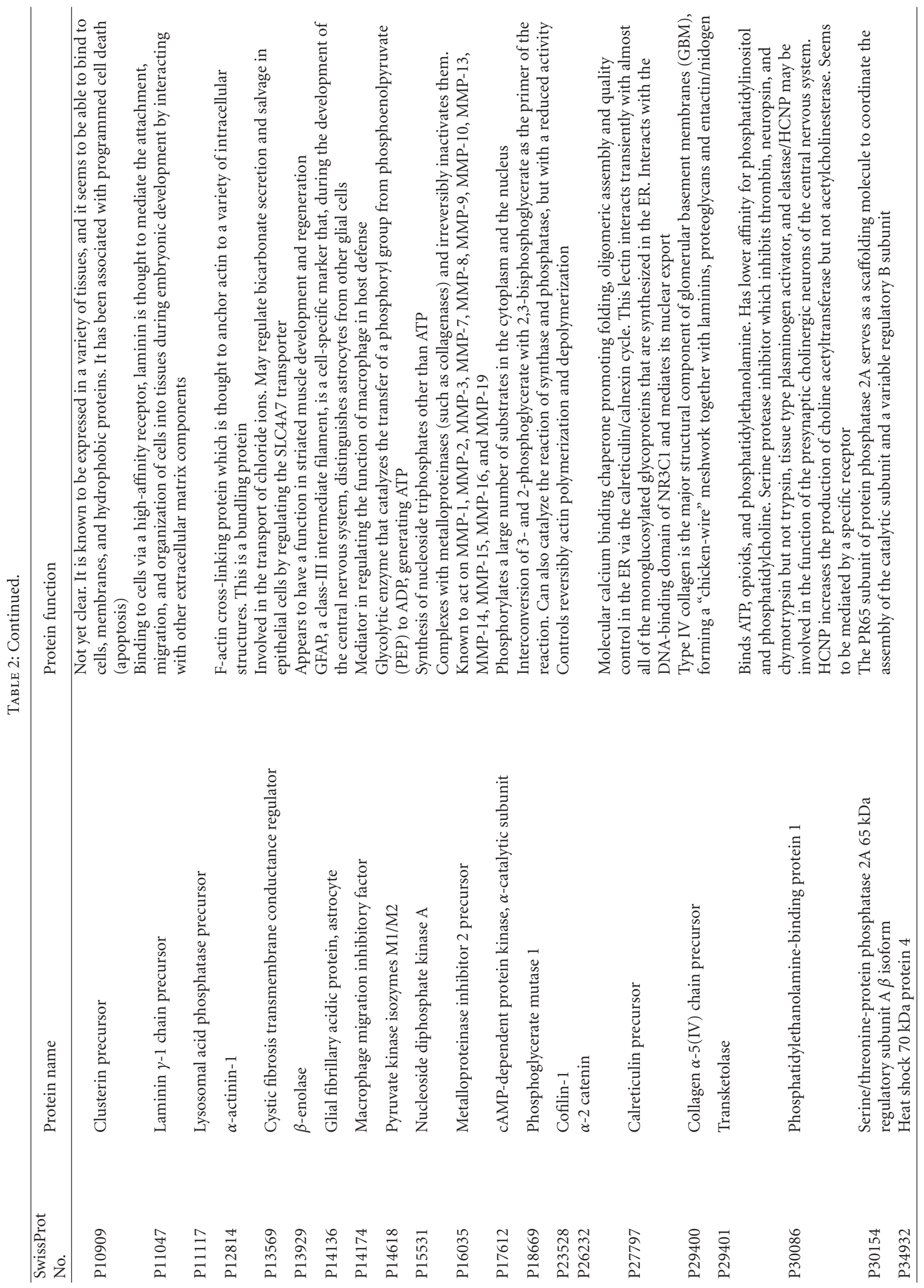




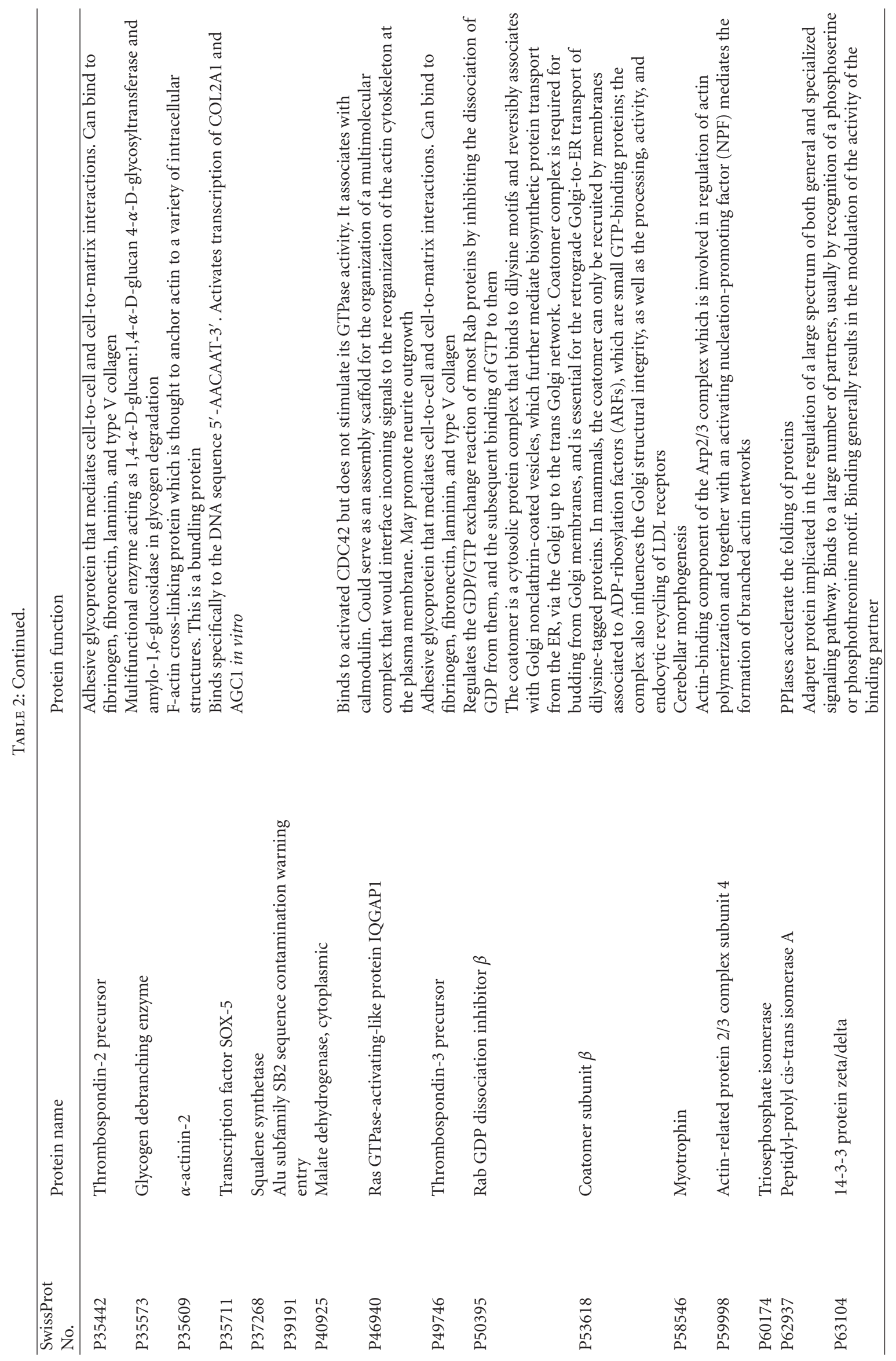




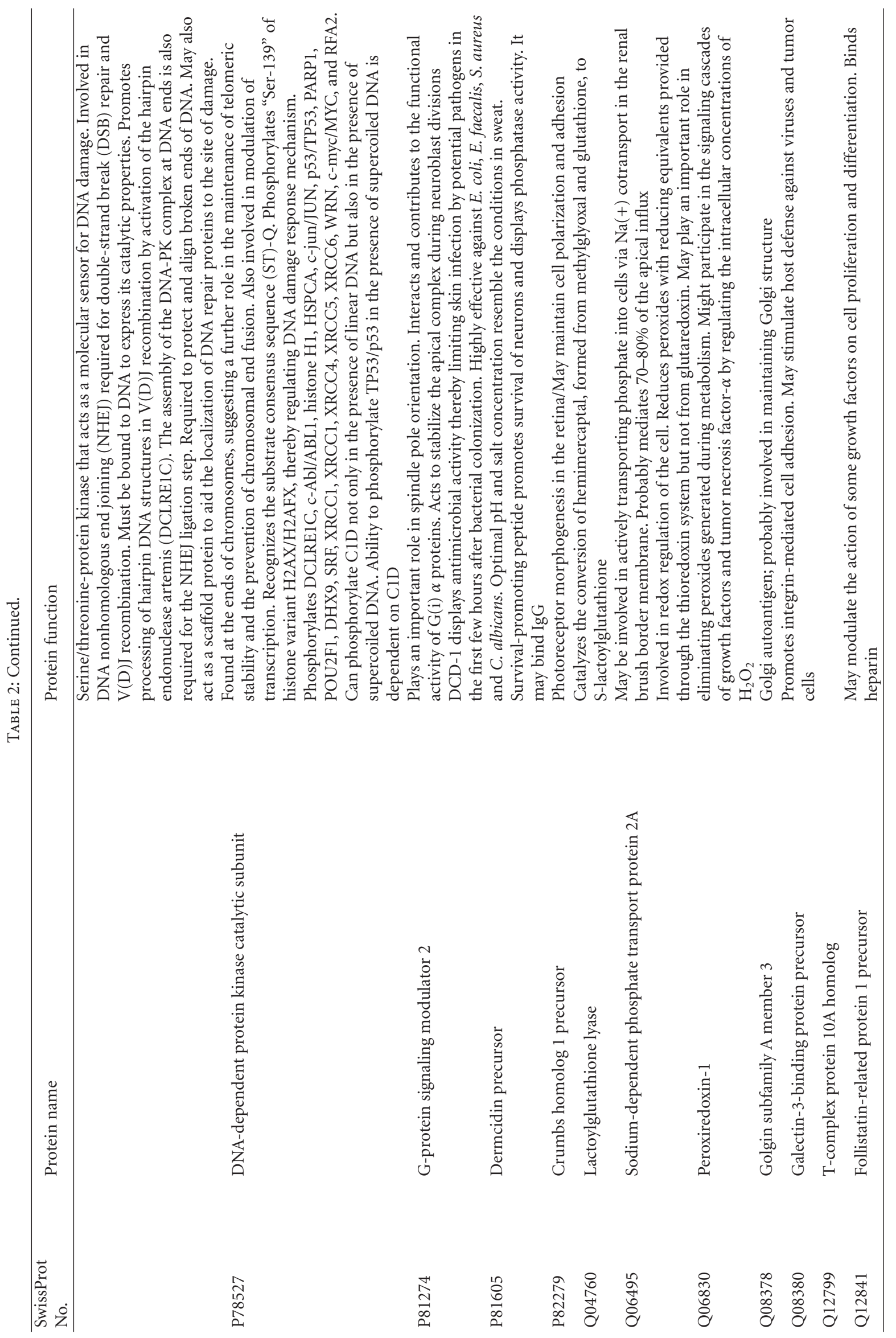




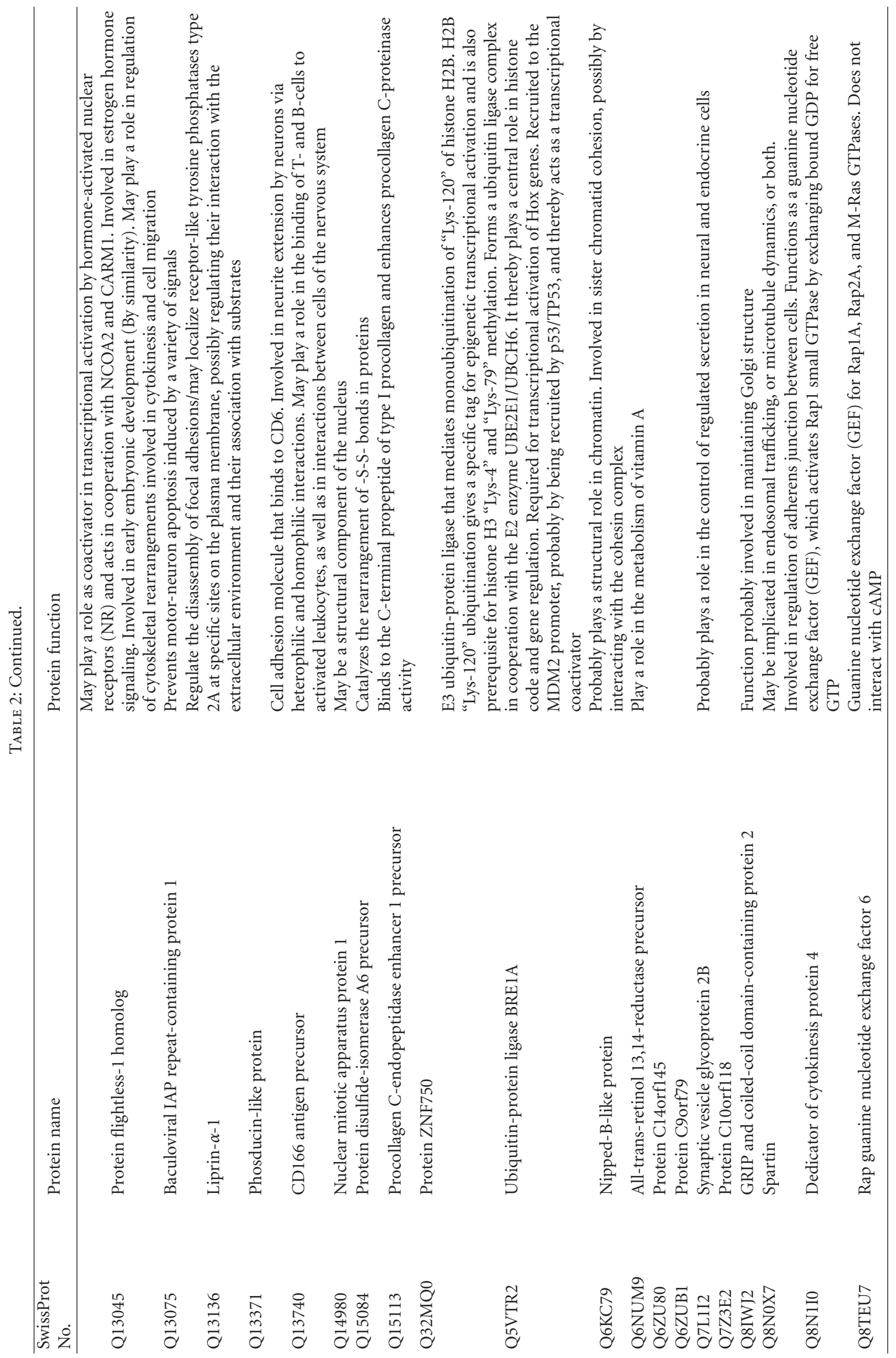




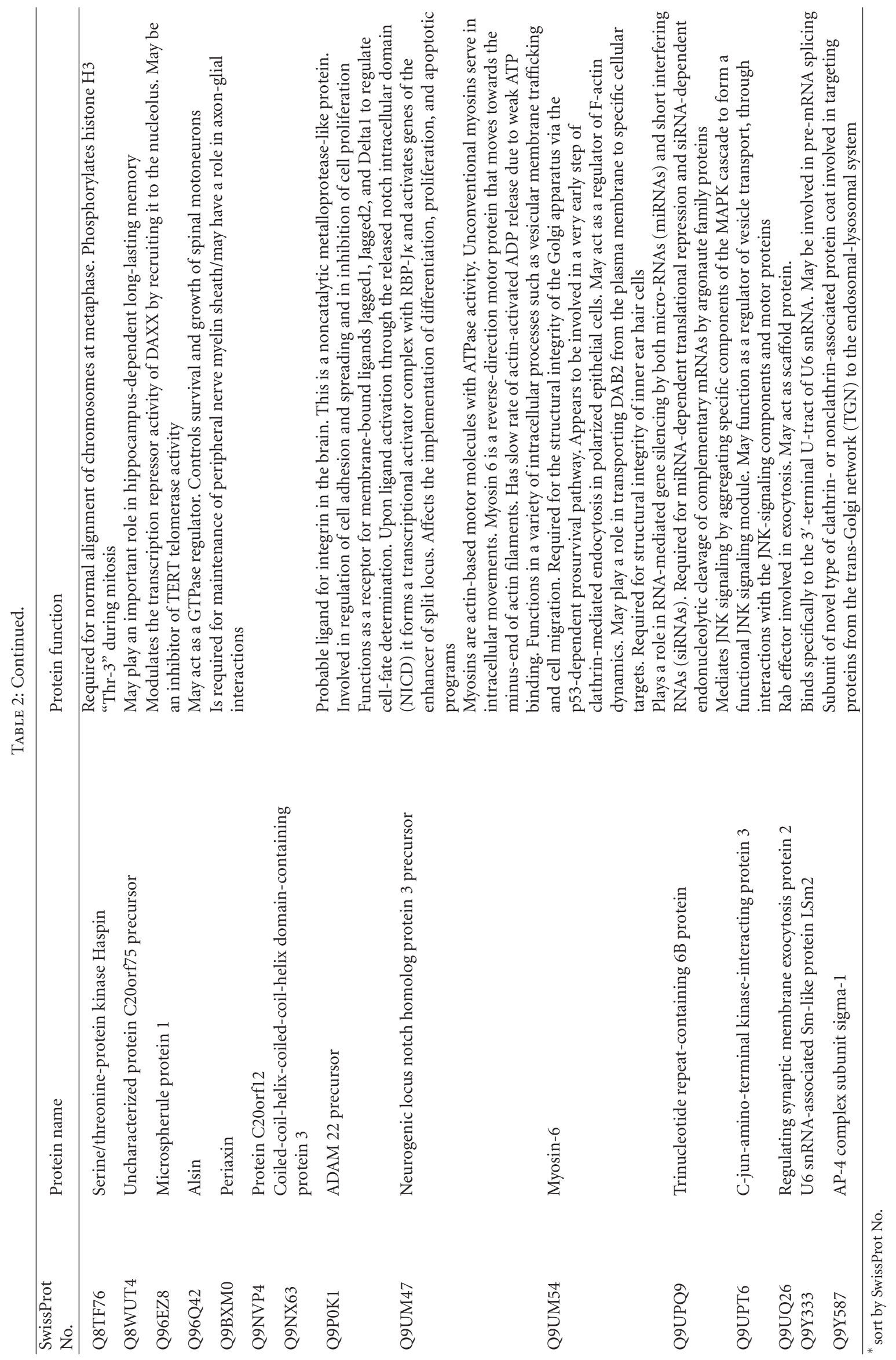


roles for ECM proteins in cell growth and differentiation can be indicated by their abilities to modulate a variety of growth factors [33].

Thrombospondin (TSP, MW 420 kDa), which belongs to a multigene family of modular modular glycoproteins, is composed of three identical subunits within a disulfide linkage. TSP is synthesized by several matrix-forming cells and is incorporated into their extracellular matrix. In several cell types, this protein supports cell growth and proliferation. As a component of ECM, TSP is involved in the regulation of mediate platelet aggregation, inflammation, and angiogenesis as well as adhesion, migration, growth, and differentiation of a number of normal and transformed cells $[34,35]$. The expression of the TSP has been also investigated during the process of differentiation of embryonal carcinoma cells, granulose cells and HL-60 cells in vitro [36-39]. Although the TSP is prevalent in differentiated cells, the induced TSP syntheses during the differentiation may function differently during neurogenesis.

In the eye, TSP-1 is localized in the epiretinal membrane and between the retinal pigment epithelial layer and Bruch's membrane, which is a cell-attachment factor with cell-specific affinity. TSP-1 production by retinal pigment epithelial cells is affected by the state of proliferation and cell density. With its anti-angiogenic activity, TSP-1 may play several biologic roles on Bruch's membrane [35]. In another report, the authors evaluated the bone marrow stromal cells (BMSCs) secretion of TSP- 1 , which is a putative mechanistic agent acting on RGCs for survival and growth [40]. The BMSC-derived TSP-1 is identified as a specific mediator of reparative processes in neurons, which functions included enhanced RGC neurite formation, cell survival, and expression of synaptophysin. It suggested that the TSP-1 signaling pathway might be an important role in neural-like differentiation in BMSCs and outgrowth in RGCs [40]. These observations suggest that the synthesis of TSP contributes to the differentiation options/alternatives of RGC- 5 cells toward a neural fate, reminiscent of their neural crest origin.

TSP-2 and SPARC (secreted protein, acidic and rich in cysteine) are classified as matricellular proteins. TSP-2 appears to play a role in reducing proliferation, while SPARC may have a positive role in progenitor cell expansion. TSP2 and SPARC have been shown to positively influence osteoblast differentiation, with the ability to limit adipogenesis $[41,42]$.

TSP-3 is structurally similar to cartilage oligomeric matrix protein (COMP/TSP-5), and was a recently described member with the calcium binding Type 3 repeats. Like Type 1 and 2 repeats, TSP- 3 is absence of the complement and contains four epidermal growth factor receptors with a distinct $\mathrm{N}$ terminus that has no significant homology to other TSPs. TSP-3 is also an oligomeric heparin binding protein present in both the cell layer and medium [43].

Galectin-3-binding protein (G3BP), also known as Mac2 binding protein, is a secreted glycoprotein with a molecular mass of $\sim 90 \mathrm{kDa}$ present in the extracellular matrix of cells. Gelectins and their binding proteins have primarily been described in cell-cell and cell-matrix interactions and play roles in autoimmunity, inflammation and tumor progression or metastasis [44]. G3BP promotes integrinmediated cell adhesion and functions in cancer progression of human tumor cells. It also binds to multiple proteins in the extracellular matrix including collagen, fibronectin, and nidogen, and to molecules mediating cell-cell and cell-matrix adhesions that are critical during tumor cell invasion and migration [45-48].

Notch-3 was the third discovered human homologue of the Drosophila melanogaster type I membrane protein notch. In Drosophila, the interaction of notch with its cellbound ligands (delta and serrate) establishes an intercellular signaling pathway that plays a key role in neural development. Members of the Notch gene family were thought to be involved as receptors for membrane-bound ligands Jagged1, Jagged2, and Delta1 in the regulation of cell fate in a variety of neurogenesis of embryos, particularly in the developing central nervous system (CNS) from the homogenous cell population of the neural tube $[49,50]$. The Notch-3 activation induces the increase of the progenitor cell number in the CNS and affected CNS development. The Notch-3 mutation may lead to cerebral autosomal dominant arteriopathy with subcortical infarcts and leukoencephalopathy (CADASIL). CADASIL leads to stroke and dementia and is the main feature of recurrent subcortical ischemic events and vascular dementia. Such mutations affect highly-conserved cysteine residues in epidermal growth factor- (EGF-) like repeat domain in the extracellular part of the receptor [51, 52].

Follistatin-related protein (FSRP) is a recently discovered glycoprotein that is highly homologous in both primary sequence and exon/intron domain structure to the activinbinding protein, follistatin (FS). FS is a secreted monomeric glycoprotein and a member of a large group of proteins containing a highly conserved module of cysteine-rich sequence termed the follistatin domain. It was first isolated from ovarian follicular fluid on the basis of its ability to suppress FSH secretion by pituitary cells in vitro [53]. This follistatin gene family includes follistatin, follistatin-related gene (FLRG) protein, follistatin-related protein (FSRP), agrin, secreted protein acidic, and it is rich in cysteine (SPARC), and Mac25 [54]. A follistatin-like sequence containing 10 conserved cysteine residues may modulate the action of some growth factors on cell proliferation and differentiation. It was also thought to be an autoantigen associated with rheumatoid arthritis [55].

SPARC, also known as osteonectin, $43 \mathrm{~K}$ protein, or $\mathrm{BM}-40$, is a $32.7 \mathrm{kDa}$ calcium- and copper-binding glycoprotein, which is a product of natural synthesis from osteoblasts, endothelial cells, and megakaryocytes. It functions as a counteradhesive protein, as a modulator of growth factor activity, and as a cell-cycle inhibitor [56]. SPARC belongs to matrix-associated factors that mediate cell-matrix interactions. Other members of this group include TSP-1 and -2, osteopontin (OPN), tenascins, and the SPARC-related proteins. Expressed during many stages of development in a variety of organisms, the expression of this matricellular protein, SPARC, is restricted in adult vertebrates primarily to tissues that undergo consistent turnover or to sites of injuries and diseases [56]. Vertebrate SPARC binds to a number of different ECM components 
including albumin, thrombospondin 1, PDGF, vitronectin, entactin/nidogen, fibrillar collagens (types I, II, III, and $\mathrm{V})$, and collagen type IV, the prevalent collagen in basement membranes [57]. The ability of SPARC to bind to several resident ECM proteins affects the expression of matrix metalloproteinases and adjusts effects of growth factors; as a counteradhesive factor of cell shape change, this supports SPARC to regulate cell interactions during their development [57]. SPARC appears to regulate cell growth through interactions with the extracellular matrix and cytokines. It is also a matricellular protein that modulates cell adhesion and proliferation and is thought to function in tissue remodeling and angiogenesis [58, 59].

Peroxiredoxin (PRDX) is a recently identified family of antioxidative proteins that includes six isoforms in mammals. They share a common reactive Cys residue in the $\mathrm{N}$-terminal region and are capable of serving as a peroxidase, involving thioredoxin and/or glutathione as the electron donor. PRDX 1-4 have an additional reactive Cys residue in the conserved C-terminal region and show $>70 \%$ amino acid sequence homology. In this capacity, they may be involved in the protection of cells from oxidative stress. Peroxiredoxin1 (PRDX1) is ubiquitously expressed and functions as an antioxidant enzyme, which reduces hydrogen peroxide and alkyl hydroperoxide and is involved in cellular proliferation, differentiation, apoptosis, and innate immunity [60]. PRDX1 may participate in the signal cascades of growth factors and tumor necrosis factor- $\alpha$ by regulating the intracellular concentrations of hydrogen peroxide [61-63]. A previous study also applied a proteomic approach to study PRDX1, -2, and -3 expressions in Alzheimer's diseases and Down's syndrome, and found a significant increase in PRDX1 expression associated with the neurodegenerative diseases [64].

The human cofilin protein has a molecular weight of approximately $21 \mathrm{kDa}$. It is a member of the actin depolymerization factor (ADF)/cofilin family. Cofilin is an essential cellular protein that can bind the barbed end of actin and is required for cell viability [65]. In cells, cofilin acts in harmony with other regulatory proteins to mediate the response of the actin cytoskeleton to extracellular signals. In vertebrates, cofilin is regulated by $\mathrm{pH}$, phosphorylation and phosphoinositides. It is involved in the translocation of the actin-cofilin complex from cytoplasm to nucleus. Cofilin plays an essential role in actin filament dynamics by enhancing depolymerization and severance of actin filaments [66]. These activities of cofilin can be abolished by phosphorylation at Ser-3; therefore, phosphorylation/dephosphorylation of cofilin at Ser-3 is regarded as one of the important mechanisms for regulating cofilin activities and actin filament dynamics [67]. Sinha et al. reported that the suppression of cofilin might lead to cancer regression [68].

Profilin-1 (PFN1) is a widely and highly expressed 14to $17-\mathrm{kDa}$ cytoplasmic and nuclear ligand protein of the microfilament system. It is a ubiquitous actin monomerbinding protein involved in actin polymerization in response to extracellular signaling pathways. PFN1 plays a central role in the regulation of de novo actin assembly by preventing spontaneous actin polymerisation through the binding of actin monomers and addition of monomeric actin to the barbed actin-filament ends [69]. The importance of profilins for normal cell proliferation, differentiation, cellular survival, motility, adhesion, migration, and cytoskeleton remodelling has been verified [69-72]. PFN1 may be a tumor suppressor because its expression was reduced in several types of invasive cancers and it was able to suppress tumorigenicity when overexpressed [73]. In addition, the immunohistochemistry analysis also showed low levels of PFN1 in several human breast cancers. Other than being a tumor suppressor, PFN1 was reported as a necessary element for differentiation of human epithelial cells [74].

Galectins are a family of structurally related carbohydrate-binding proteins and widely distributed in nematodes, insects, and porifer, as well as vertebrates and fungi [75]. They are defined by their affinity for poly$\mathrm{N}$-acetyllactosamine-enriched glycoconjugates and sequence similarities in the carbohydrate recognition domain. The galectins are a family of $\beta$-galactoside-binding proteins implicated in modulating cell-cell and cell-matrix interactions, which would be required for protein secretion through the classical secretory pathways found in the extracellular space [76].

Galectin-1 is expressed during human embryogenesis, and many adult cell types express and secrete galectin-1 into the extracellular matrix [76]. Galectin-1 contributes to different events associated with cancer biology, including tumour transformation, proliferation, differentiation, cell cycle regulation, growth arrest, apoptosis, cell adhesion, migration, inflammation, and inhibition of full cell activation [77]. A previous study has shown that galectin-1 induced sustained exposure of phosphatidylserine on the cell surface in a carbohydrate-dependent fashion, but phosphatidylserine exposure is not associated with cell death by apoptosis and does not affect cell viability. There is evidence that galectin-1 contributes to tumour evasion of immune responses [78].

A positive correlation has recently been shown between galectin-3 expression and the degree of malignant transformation in certain types of cell lines, and the amount of galectin-3 expression is expected to possibly serve as an index of degree for neoplastic transformation, tumor cell survival, angiogenesis, tumor metastasis, and tumor malignancy [79, $80]$. Recent studies have revealed that intracellular galectin3 exhibits the activity to suppress drug-induced apoptosis and anoikis that contribute to cell survival. Resistance to apoptosis is essential for cancer cell survival and plays a role in tumor progression [81].

Moreover, both galectin- 1 and galectin-3 expressions are necessary for the initiation of the transformed phenotype of tumors. Inhibition of galectin-1 expression can suppress the transformed phenotype of human glioma cells [82]. In addition, following the inhibition of galectin-3 expression, breast carcinoma cells and thyroid papillary carcinoma cells lose their transformed characteristic phenotypes in cell culture $[83,84]$.

Myotrophin, a $12 \mathrm{kDa}$ protein consists of 117 amino acids, has a potential role in cerebellar morphogenesis and 
may be involved in differentiation of cerebellar neurons, particularly of granule cells, and associated with cardiac hypertrophy. It appears to be a primary modulator for myocardial cell growth and differentiation [85]. Myotrophin accelerates myocyte growth by stimulating protein synthesis and may be correlated with cardiac hypertrophy in the pathogenesis, where it is involved in the conversion of NF- $\kappa \mathrm{B}$ p50-p65 heterodimers to p50-p50 and p65-p65 homodimers as well as in the normal development of cardiac myocytes [86]. A previous study also indicated that myotrophin may be involved in the upregulation of myofibrillar protein and the activation of cardiac gene transcription during the growth and hypertrophy of myocardium; thus, the induction of early response of gene expression may be linked to this response [87].

The 132 proteins identified in this study may be involved in some biologic processes that are associated with cell differentiation, proliferation, and adhesion. We have tested some proteins incorporated into the medium; however, none of those proteins can solely induce cell differentiation. The results form a database with a diversity and relative abundance of various proteins found in the HNPE cell-secreted proteins. The database provides not only information on the nature of protein contents in HNPE cells but also potential proteins to be examined in further investigations.

\section{Conclusions}

In this study, we established the first secretome database for HNPE cells. The experimental results obtained by SDSPAGE and nano-high performance liquid chromatography electrospray ionization tandem mass spectrometry (nanoHPLC-ESI-MS/MS) system revealed the identification of 132 unique proteins from HNPE cell secretome. Among these 132 proteins identified with higher confidence levels, some proteins have been reported involving in cell differentiation, such as thrombospondin-1, 2, 3 precursor, galectin-3-binding protein, neurogenic locus notch homolog protein 3, follistatin-related protein 1 precursor, sPARC precursor, peroxiredoxin-1, cofilin 1, profilin 1, galectin-1, and myotrophin. However, none of those proteins can induce cell differentiation solely. This list serves as a starting point for buildingup a comprehensive database of the proteome of this cell-line. The database can include diverse repertoires of proteins expressed by HNPE cells. All of this data will enhance our understanding of the molecular mechanisms involved in maintaining the differentiated states of HNPE cells and directing their differentiation and, in turn, will bring us closer to fulfill the vast clinical potentials of the cells.

In conclusion, we have demonstrated that RGC-5 cells upon coculturing with HNPE cell conditioned SF-medium developed a differentiated morphology and continued to express the necessary RGC markers. The differentiated RGC5 cells would therefore be useful to study apoptotic pathways of retinal ganglion cell death. The findings from this study may have significant impacts on HNPE cell biology and cell engineering.

\section{Acknowledgments}

This paper was supported by research Grants Q097004 from the Kaohsiung Medical University Research Foundation, NSC96-2321-B-037-006, NSC-099-2811-E-224-002, and NSC97-2320-B-037-012-MY3 from the National Science Council, Taiwan.

\section{References}

[1] V. R. Rao, R. R. Krishnamoorthy, and T. Yorio, "Endothelin1 mediated regulation of extracellular matrix collagens in cells of human lamina cribrosa," Experimental Eye Research, vol. 86, no. 6, pp. 886-894, 2008.

[2] M. Hernández, J. H. Urcola, and E. Vecino, "Retinal ganglion cell neuroprotection in a rat model of glaucoma following brimonidine, latanoprost or combined treatments," Experimental Eye Research, vol. 86, no. 5, pp. 798-806, 2008.

[3] H. Quigley and A. T. Broman, "The number of people with glaucoma worldwide in 2010 and 2020," British Journal of Ophthalmology, vol. 90, no. 3, pp. 262-267, 2006.

[4] H. A. Quigley, "Glaucoma: macrocosm to microcosm the Friedenwald lecture," Investigative Ophthalmology and Visual Science, vol. 46, no. 8, pp. 2663-2670, 2005.

[5] J. E. Morgan, H. Uchida, and J. Caprioli, "Retinal ganglion cell death in experimental glaucoma," British Journal of Ophthalmology, vol. 84, no. 3, pp. 303-310, 2000.

[6] G. R. Howell, R. T. Libby, T. C. Jakobs et al., "Axons of retinal ganglion cells are insulted in the optic nerve early in DBA/2J glaucoma," Journal of Cell Biology, vol. 179, no. 7, pp. 15231537, 2007.

[7] N. A. Castle, "Aquaporins as targets for drug discovery," Drug Discovery Today, vol. 10, no. 7, pp. 485-493, 2005.

[8] R. W. Rodieck, The First Steps in Seeing, Sinauer Associates, Sunderland, Mass, USA, 1998.

[9] B. Schwartz, J. C. Rieser, and S. L. Fishbein, "Fluorescein angiographic defects of the optic disc in glaucoma," Archives of Ophthalmology, vol. 95, no. 11, pp. 1961-1974, 1977.

[10] C. J. Barnstable and U. C. Drager, "Thy-1 antigen: a ganglion cell specific marker in rodent retina," Neuroscience, vol. 11, no. 4, pp. 847-855, 1984.

[11] Z. Q. Xiang, B. B. Knowles, J. W. McCarrick, and H. C. J. Ertl, "Immune effector mechanisms required for protection to rabies virus," Virology, vol. 214, no. 2, pp. 398-404, 1995.

[12] Y. Otori, S. Kusaka, A. Kawasaki, H. Morimura, A. Miki, and Y. Tano, "Protective effect of nilvadipine against glutamate neurotoxicity in purified retinal ganglion cells," Brain Research, vol. 961, no. 2, pp. 213-219, 2003.

[13] M. Coca-Prados, J. Escribano, and J. Ortego, "Differential gene expression in the human ciliary epithelium," Progress in Retinal and Eye Research, vol. 18, no. 3, pp. 403-429, 1999.

[14] J. Escribano, J. Ortego, and M. Coca-Prados, "Isolation and characterization of cell-specific cDNA clones from a subtractive library of the ocular ciliary body of a single normal human donor: transcription and synthesis of plasma proteins," Journal of Biochemistry, vol. 118, no. 5, pp. 921-931, 1995.

[15] J. Ortego and M. Coca-Prados, "Molecular characterization and differential gene induction of the neuroendocrine-specific genes neurotensin, neurotensin receptor, PC1, PC2, and 7B2 in the human ocular ciliary epithelium," Journal of Neurochemistry, vol. 69, no. 5, pp. 1829-1839, 1997. 
[16] N. J. van Bergen, J. P. Wood, G. Chidlow et al., "Recharacterization of the RGC-5 retinal ganglion cell line," Investigative Ophthalmology and Visual Science, vol. 50, no. 9, pp. 42674272, 2009.

[17] Y. C. Tyan, H. Y. Wu, W. C. Su, P. W. Chen, and P. C. Liao, "Proteomic analysis of human pleural effusion," Proteomics, vol. 5, no. 4, pp. 1062-1074, 2005.

[18] Y. C. Tyan, H. Y. Wu, W. W. Lai, W. C. Su, and P. C. Liao, "Proteomic profiling of human pleural effusion using two-dimensional nano liquid chromatography tandem mass spectrometry," Journal of Proteome Research, vol. 4, no. 4, pp. 1274-1286, 2005.

[19] A. Pandey, A. V. Podtelejnikov, B. Blagoev, X. R. Bustelo, M. Mann, and H. F. Lodish, "Analysis of receptor signaling pathways by mass spectrometry: identification of vav-2 as a substrate of the epidermal and platelet-derived growth factor receptors," Proceedings of the National Academy of Sciences of the United States of America, vol. 97, no. 1, pp. 179-184, 2000.

[20] C. O'Donovan, M. J. Martin, A. Gattiker, E. Gasteiger, A. Bairoch, and R. Apweiler, "High-quality protein knowledge resource: SWISS-PROT and TrEMBL," Briefings in Bioinformatics, vol. 3, no. 3, pp. 275-284, 2002.

[21] E. Gasteiger, A. Gattiker, C. Hoogland, I. Ivanyi, R. D. Appel, and A. Bairoch, "ExPASy: the proteomics server for in-depth protein knowledge and analysis," Nucleic Acids Research, vol. 31, no. 13, pp. 3784-3788, 2003.

[22] S. R. Piersma, U. Fiedler, S. Span et al., "Workflow comparison for label-free, quantitative secretome proteomics for cancer biomarker discovery: method evaluation, differential analysis, and verification in serum," Journal of Proteome Research, vol. 9, no. 4, pp. 1913-1922, 2010.

[23] M. Makridakis and A. Vlahou, "Secretome proteomics for discovery of cancer biomarkers," Journal of Proteomics, vol. 73, no. 12, pp. 2291-2305, 2010.

[24] Y. Hathout, "Approaches to the study of the cell secretome," Expert Review of Proteomics, vol. 4, no. 2, pp. 239-248, 2007.

[25] I. Surgucheva, A. D. Weisman, J. L. Goldberg, A. Shnyra, and A. Surguchov, " $\gamma$-synuclein as a marker of retinal ganglion cells," Molecular Vision, vol. 14, pp. 1540-1548, 2008.

[26] L. J. Frassetto, C. R. Schlieve, C. J. Lieven et al., "Kinasedependent differentiation of a retinal ganglion cell precursor," Investigative Ophthalmology and Visual Science, vol. 47, no. 1, pp. 427-438, 2006.

[27] J. P. Wood, G. Chidlow, T. Tran, J. G. Crowston, and R. J. Casson, "A comparison of differentiation protocols for RGC5 cells," Investigative Ophthalmology \& Visual Science, vol. 51, no. 7, pp. 3774-3783, 2010.

[28] R. R. Krishnamoorthy, P. Agarwal, G. Prasanna et al., "Characterization of a transformed rat retinal ganglion cell line," Molecular Brain Research, vol. 86, no. 1-2, pp. 1-12, 2001.

[29] L. Gan, S. W. Wang, Z. Huang, and W. H. Klein, "POU domain factor Brn-3b is essential for retinal ganglion cell differentiation and survival but not for initial cell fate specification," Developmental Biology, vol. 210, no. 2, pp. 469480, 1999.

[30] X. Mu and W. H. Klein, "A gene regulatory hierarchy for retinal ganglion cell specification and differentiation," Seminars in Cell and Developmental Biology, vol. 15, no. 1, pp. 115-123, 2004.

[31] J. D. Jaffe, H. C. Berg, and G. M. Church, "Proteogenomic mapping as a complementary method to perform genome annotation," Proteomics, vol. 4, no. 1, pp. 59-77, 2004.

[32] Y. Guo, S. F. Ma, D. Grigoryev, J. Van Eyk, and J. G. N. Garcia, "1-DE MS and 2-D LC-MS analysis of the mouse bronchoalveolar lavage proteome," Proteomics, vol. 5, no. 17, pp. 4608-4624, 2005.

[33] N. M. Kumar, S. L. Sigurdson, D. Sheppard, and J. S. LwebugaMukasa, "Differential modulation of integrin receptors and extracellular matrix laminin by transforming growth factor$\beta 1$ in rat alveolar epithelial cells," Experimental Cell Research, vol. 221, no. 2, pp. 385-394, 1995.

[34] V. Alessandra, D. M. Lucia, G. Giuseppe et al., "Thrombospondin-1 is a mediator of the neurotypic differentiation induced by EGF in thymic epithelial cells," Experimental Cell Research, vol. 248, no. 1, pp. 79-86, 1999.

[35] H. Miyajima-Uchida, H. Hayashi, R. Beppu et al., "Production and accumulation of thrombospondin-1 in human retinal pigment epithelial cells," Investigative Ophthalmology and Visual Science, vol. 41, no. 2, pp. 561-567, 2000.

[36] D. J. Liska, R. Hawkins, K. Wikstrom, and P. Bornstein, "Modulation of thrombospondin expression during differentiation of embryonal carcinoma cells," Journal of Cellular Physiology, vol. 158, no. 3, pp. 495-505, 1994.

[37] S. J. Suchard, P. J. Mansfield, and V. M. Dixit, "Modulation of thrombospondin receptor expression during HL-60 cell differentiation," Journal of Immunology, vol. 152, no. 2, pp. 877-888, 1994.

[38] M. Dreyfus, R. Dardik, B. S. Suh, A. Amsterdam, and J. Lahav, "Differentiation-controlled synthesis and binding of thrombospondin to granulosa cells," Endocrinology, vol. 130, no. 5, pp. 2565-2570, 1992.

[39] K. S. O'Shea and V. M. Dixit, "Unique distribution of the extracellular matrix component thrombospondin in the developing mouse embryo," Journal of Cell Biology, vol. 107, no. 6, pp. 2737-2748, 1988.

[40] K. Yu, J. Ge, J. B. Summers et al., "TSP-1 secreted by one marrow stroma cells contributes to retinal ganglion cell neurite outgrowth and survival," PLoS One, vol. 3, no. 6, Article ID e2470, pp. 1-11, 2008.

[41] A. E. Canfield, A. B. Sutton, J. A. Hoyland, and A. M. Schor, "Association of thrombospondin-1 with osteogenic differentiation of retinal pericytes in vitro," Journal of Cell Science, vol. 109, no. 2, pp. 343-353, 1996.

[42] A. M. Delany and K. D. Hankenson, "Thrombospondin2 and SPARC/osteonectin are critical regulators of bone remodeling," Journal of Cell Communication and Signaling, vol. 3, no. 3-4, pp. 227-238, 2009.

[43] A. N. Qabar, Z. Lin, F. W. Wolf, K. S. O'Shea, J. Lawler, and V. M. Dixit, "Thrombospondin 3 is a developmentally regulated heparin binding protein," Journal of Biological Chemistry, vol. 269, no. 2, pp. 1262-1269, 1994.

[44] M. Blostein, J. Cuerquis, and J. Galipeau, "Galectin 3-binding protein is a potential contaminant of recombinantly produced factor IX," Haemophilia, vol. 13, no. 6, pp. 701-706, 2007.

[45] T. Plavina, E. Wakshull, W. S. Hancock, and M. Hincapie, "Combination of abundant protein depletion and multilectin affinity chromatography (M-LAC) for plasma protein biomarker discovery," Journal of Proteome Research, vol. 6, no. 2, pp. 662-671, 2007.

[46] G. Calabrese, I. Sures, F. Pompetti, G. Natoli, G. Palka, and S. Iacobelli, "The gene (LGALS3BP) encoding the serum protein $90 \mathrm{~K}$, associated with cancer and infection by the human immunodeficiency virus, maps at 17q25," Cytogenetics and Cell Genetics, vol. 69, no. 3-4, pp. 223-225, 1995.

[47] K. Koths, E. Taylor, R. Halenbeck, C. Casipit, and A. Wang, "Cloning and characterization of a human Mac-2-binding protein, a new member of the superfamily defined by the macrophage scavenger receptor cysteine-rich domain," Journal 
of Biological Chemistry, vol. 268, no. 19, pp. 14245-14249, 1993.

[48] Y. Fukaya, H. Shimada, L. C. Wang, E. Zandi, and Y. A. DeClerck, "Identification of galectin-3-binding protein as a factor secreted by tumor cells that stimulates interleukin-6 expression in the bone marrow stroma," Journal of Biological Chemistry, vol. 283, no. 27, pp. 18573-18581, 2008.

[49] S. A. Sullivan, L. K. Barthel, B. L. Largent, and P. A. Raymond, "A goldfish Notch-3 homologue is expressed in neurogenic regions of embryonic, adult and regenerating brain and retina," Developmental Genetics, vol. 20, no. 3, pp. 208-223, 1997.

[50] Y. Qu, K. Sakamoto, S. Takeda, T. Kayano, M. Takagi, and K. Katsube, "Differential expression of notch genes in the neurogenesis of mouse embryos," Oral Medicine \& Pathology, vol. 3, pp. 21-28, 1998.

[51] M. Lardelli, R. Williams, T. Mitsiadis, and U. Lendahl, "Expression of the Notch 3 intracellular domain in mouse central nervous system progenitor cells is lethal and leads to disturbed neural tube development," Mechanisms of Development, vol. 59, no. 2, pp. 177-190, 1996.

[52] A. Joutel, C. Corpechot, A. Ducros et al., "Tournier-Lasserve, Notch3 mutations in CADASIL, a hereditary adult-onset condition causing stroke and dementia," Nature, vol. 383, no. 6602, pp. 707-710, 1996.

[53] D. V. Tortoriello, Y. Sidis, D. A. Holtzman, W. E. Holmes, and A. L. Schneyer, "Human follistatin-related protein: a structural homologue of follistatin with nuclear localization," Endocrinology, vol. 142, no. 8, pp. 3426-3434, 2001.

[54] J. Liu, T. Vänttinen, C. Hydén-Granskog, and R. Voutilainen, "Regulation of follistatin-related gene (FLRG) expression by protein kinase $\mathrm{C}$ and prostaglandin $\mathrm{E}(2)$ in cultured granulosa-luteal cells," Molecular Human Reproduction, vol. 8, no. 11, pp. 992-997, 2002.

[55] Y. Ehara, D. Sakurai, N. Tsuchiya et al., "Follistatin-related protein gene (FRP) is expressed in the synovial tissues of rheumatoid arthritis, but its polymorphisms are not associated with genetic susceptibility," Clinical and Experimental Rheumatology, vol. 22, no. 6, pp. 707-712, 2004.

[56] R. A. Brekken and E. H. Sage, "SPARC, a matricellular protein: at the crossroads of cell-matrix communication," Matrix Biology, vol. 19, no. 8, pp. 815-827, 2001.

[57] A. D. Bradshaw and E. H. Sage, "SPARC, a matricellular protein that functions in cellular differentiation and tissue response to injury," Journal of Clinical Investigation, vol. 107, no. 9, pp. 1049-1054, 2001.

[58] A. D. Bradshaw, J. A. Bassuk, A. Francki, and E. H. Sage, "Expression and purification of recombinant human SPARC produced by baculovirus," Molecular Cell Biology Research Communications, vol. 3, no. 6, pp. 345-351, 2000.

[59] M. J. Alvarez, F. Prada, E. Salvatierra et al., "Secreted protein acidic and rich in cysteine produced by human melanoma cells modulates polymorphonuclear leukocyte recruitment and antitumor cytotoxic capacity," Cancer Research, vol. 65, no. 12, pp. 5123-5132, 2005.

[60] J. Nawarak, R. Huang-Liu, S. H. Kao et al., "Proteomics analysis of A375 human malignant melanoma cells in response to arbutin treatment," Biochimica et Biophysica Acta, vol. 1794, no. 2, pp. 159-167, 2009.

[61] K. A. Daly, C. Lefévre, K. Nicholas, E. Deane, and P. Williamson, "Characterization and expression of Peroxiredoxin 1 in the neonatal tammar wallaby (Macropus eugenii)," Comparative Biochemistry and Physiology $-B$, vol. 149, no. 1, pp. 108-119, 2008.
[62] W. Lee, K. S. Choi, J. Riddell et al., "Human peroxiredoxin 1 and 2 are not duplicate proteins: the unique presence of CYS83 in Prx1 underscores the structural and functional differences between Prx1 and Prx2," Journal of Biological Chemistry, vol. 282, no. 30, pp. 22011-22022, 2007.

[63] P. Karihtala, A. Mäntyniemi, S. W. Kang, V. L. Kinnula, and Y. Soini, "Peroxiredoxins in breast carcinoma," Clinical Cancer Research, vol. 9, no. 9, pp. 3418-3424, 2003.

[64] S. H. Kim, M. Fountoulakis, N. Cairns, and G. Lubec, "Protein levels of human peroxiredoxin subtypes in brains of patients with Alzheimer's disease and Down Syndrome," Journal of Neural Transmission, Supplement, no. 61, pp. 223-235, 2001.

[65] P. Lappalainen and D. G. Drubin, "Cofilin promotes rapid actin filament turnover in vivo," Nature, vol. 388, no. 6637, pp. 78-82, 1997.

[66] A. McGough, B. Pope, W. Chiu, and A. Weeds, "Cofilin changes the twist of F-actin: implications for actin filament dynamics and cellular function," Journal of Cell Biology, vol. 138, no. 4, pp. 771-781, 1997.

[67] J. Toshima, J. Y. Toshima, T. Amano, N. Yang, S. Narumiya, and K. Mizuno, "Cofilin phosphorylation by protein kinase testicular protein kinase 1 and its role in integrin-mediated actin reorganization and focal adhesion formation," Molecular Biology of the Cell, vol. 12, no. 4, pp. 1131-1145, 2001.

[68] P. Sinha, G. Hutter, E. Kottgen, M. Dietel, D. Schadendorf, and H. Lage, "Increased expression of epidermal fatty acid binding protein, cofilin, and 14-3-3-sigma (stratifin) detected by two-dimensional gel electrophoresis, mass spectrometry and microsequencing of drug-resistant human adenocarcinoma of the pancreas," Electrophoresis, vol. 20, pp. 2952-2960, 1999.

[69] W. Witke, J. D. Sutherland, A. Sharpe, M. Arai, and D. J. Kwiatkowski, "Profilin I is essential for cell survival and cell division in early mouse development," Proceedings of the National Academy of Sciences of the United States of America, vol. 98, no. 7, pp. 3832-3836, 2001.

[70] M. Haugwitz, A. A. Noegel, J. Karakesisoglou, and M. Schleicher, "Dictyostelium amoebae that lack G-actin-sequestering profilins show defects in F-actin content, cytokinesis, and development," Cell, vol. 79, no. 2, pp. 303-314, 1994.

[71] E. M. Verheyen and L. Cooley, "Profilin mutations disrupt multiple actin-dependent processes during Drosophila development," Development, vol. 120, no. 4, pp. 717-728, 1994.

[72] D. J. Mazzatti, G. Pawelec, R. Longdin, J. R. Powell, and R. J. Forsey, "SELDI-TOF-MS ProteinChip array profiling of Tcell clones propagated in long-term culture identifies human profilin-1 as a potential bio-marker of immunosenescence," Proteome Science, vol. 5, article 7, pp. 1-13, 2007.

[73] L. Zou, M. Jaramillo, D. Whaley et al., "Profilin-1 is a negative regulator of mammary carcinoma aggressiveness," British Journal of Cancer, vol. 97, no. 10, pp. 1361-1371, 2007.

[74] N. Wittenmayer, B. Jandrig, M. Rothkegel et al., “Tumor suppressor activity of profilin requires a functional actin binding site," Molecular Biology of the Cell, vol. 15, no. 4, pp. 1600-1608, 2004.

[75] J. Hirabayashi, T. Hashidate, Y. Arata et al., "Oligosaccharide specificity of galectins: a search by frontal affinity chromatography," Biochimica et Biophysica Acta, vol. 1572, no. 2-3, pp. 232-254, 2002.

[76] F. A. Van Den Brûle, P. L. Fernandez, C. Buicu et al., "Differential expression of galectin-1 and galectin-3 during first trimester human embryogenesis," Developmental Dynamics, vol. 209, no. 4, pp. 399-405, 1997.

[77] G. A. Rabinovich, "Galectin-1 as a potential cancer target," British Journal of Cancer, vol. 92, no. 7, pp. 1188-1192, 2005. 
[78] K. Stowell, N. Pollock, and E. Langton, "Perinatal diagnosis of malignant hyperthermia susceptibility," Anaesthesia and Intensive Care, vol. 35, no. 3, pp. 454-455, 2007.

[79] H. J. Gabius, "Concepts of tumor lectinology," Cancer Investigation, vol. 15, no. 5, pp. 454-464, 1997.

[80] H. Legendre, C. Decaestecker, N. Nagy et al., "Prognostic values of galectin-3 and the macrophage migration inhibitory factor (MIF) in human colorectal cancers," Modern Pathology, vol. 16, no. 5, pp. 491-504, 2003.

[81] S. Nakahara, N. Oka, and A. Raz, "On the role of galectin-3 in cancer apoptosis," Apoptosis, vol. 10, no. 2, pp. 267-275, 2005.

[82] K. Goldring, G. E. Jones, R. Thiagarajah, and D. J. Watt, "The effect of galectin-1 on the differentiation of fibroblasts and myoblasts in vitro," Journal of Cell Science, vol. 115, no. 2, pp. 355-366, 2002.

[83] H. P. Hahn, M. Pang, J. He et al., "Galectin-1 induces nuclear translocation of endonuclease $\mathrm{G}$ in caspase- and cytochrome c-independent T cell death," Cell Death and Differentiation, vol. 11, no. 12, pp. 1277-1286, 2004.

[84] J. Ellerhorst, T. Nguyen, D. N. Cooper, Y. Estrov, D. Lotan, and R. Lotan, "Induction of differentiation and apoptosis in the prostate cancer cell line LNCaP by sodium butyrate and galectin-1," International Journal of Oncology, vol. 14, pp. 225232, 1999.

[85] R. J. O'Brien, I. Loke, J. E. Davies, I. B. Squire, and L. L. Ng, "Myotrophin in human heart failure," Journal of the American College of Cardiology, vol. 42, no. 4, pp. 719-725, 2003.

[86] P. Sil, D. Mukherjee, and S. Sen, "Quantification of myotrophin from spontaneously hypertensive and normal rat hearts," Circulation Research, vol. 76, no. 6, pp. 1020-1027, 1995.

[87] D. P. Mukherjee, C. F. McTiernan, and S. Sen, "Myotrophin induces early response genes and enhances cardiac gene expression," Hypertension, vol. 21, no. 2, pp. 142-148, 1993. 

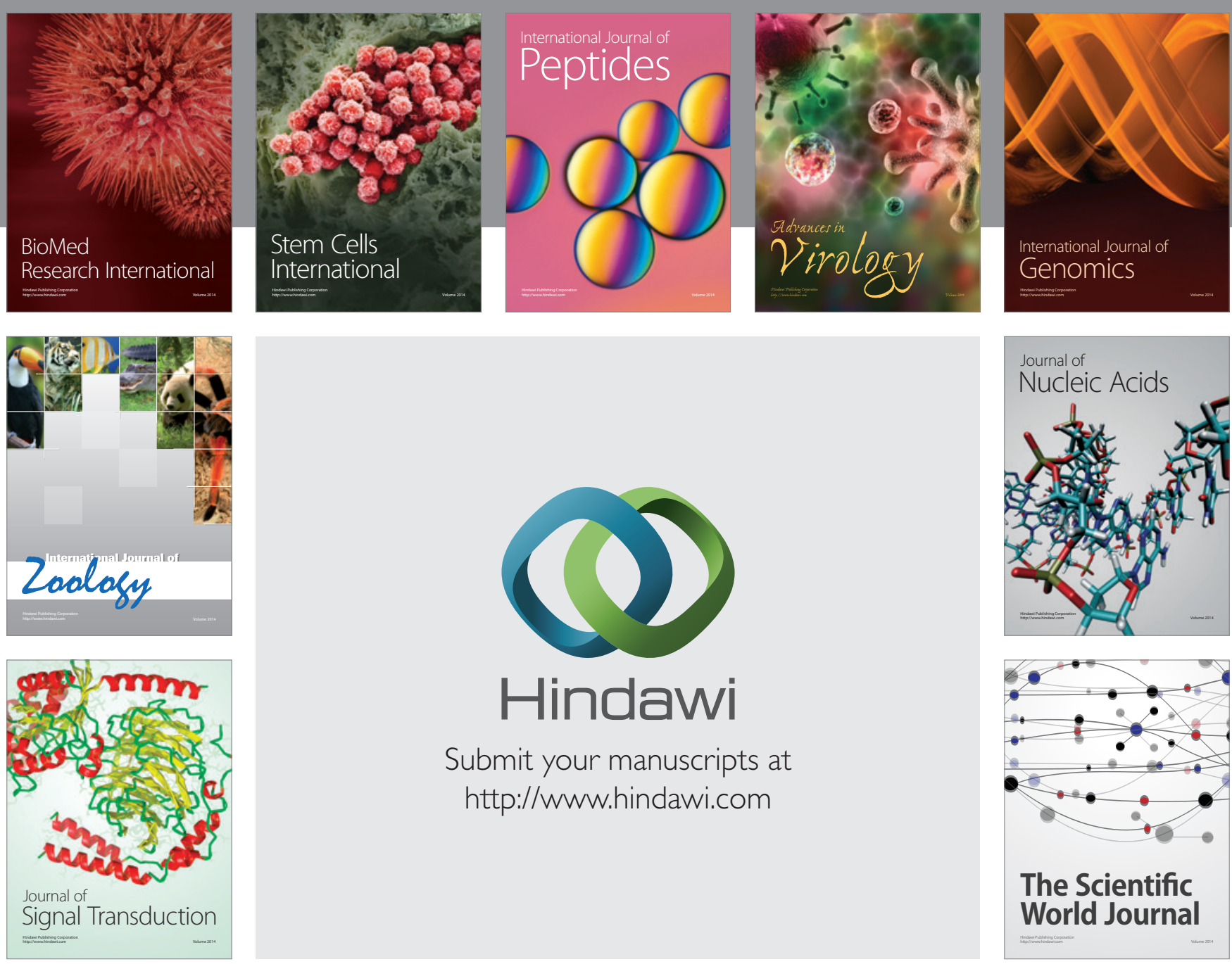

Submit your manuscripts at

http://www.hindawi.com
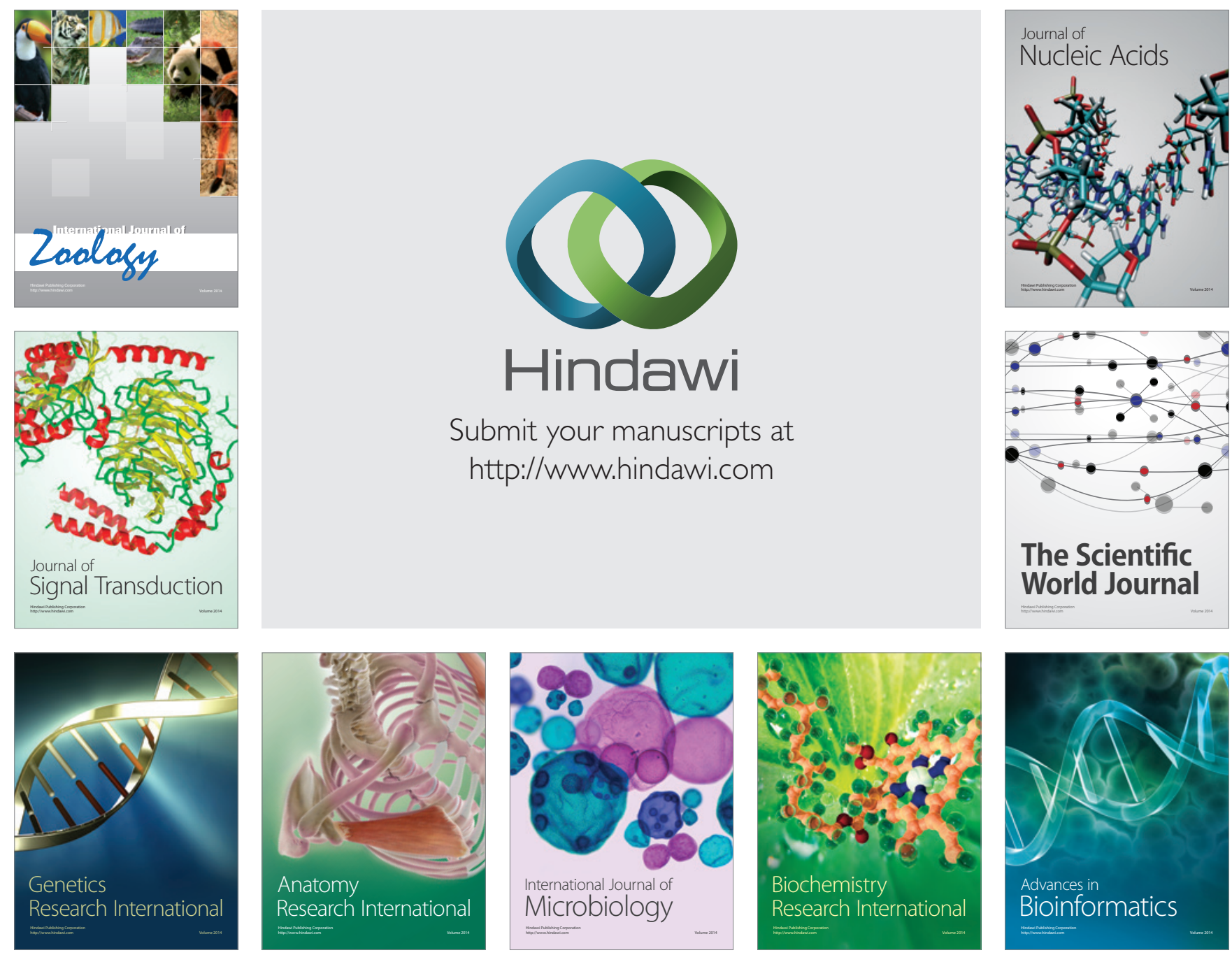

The Scientific World Journal
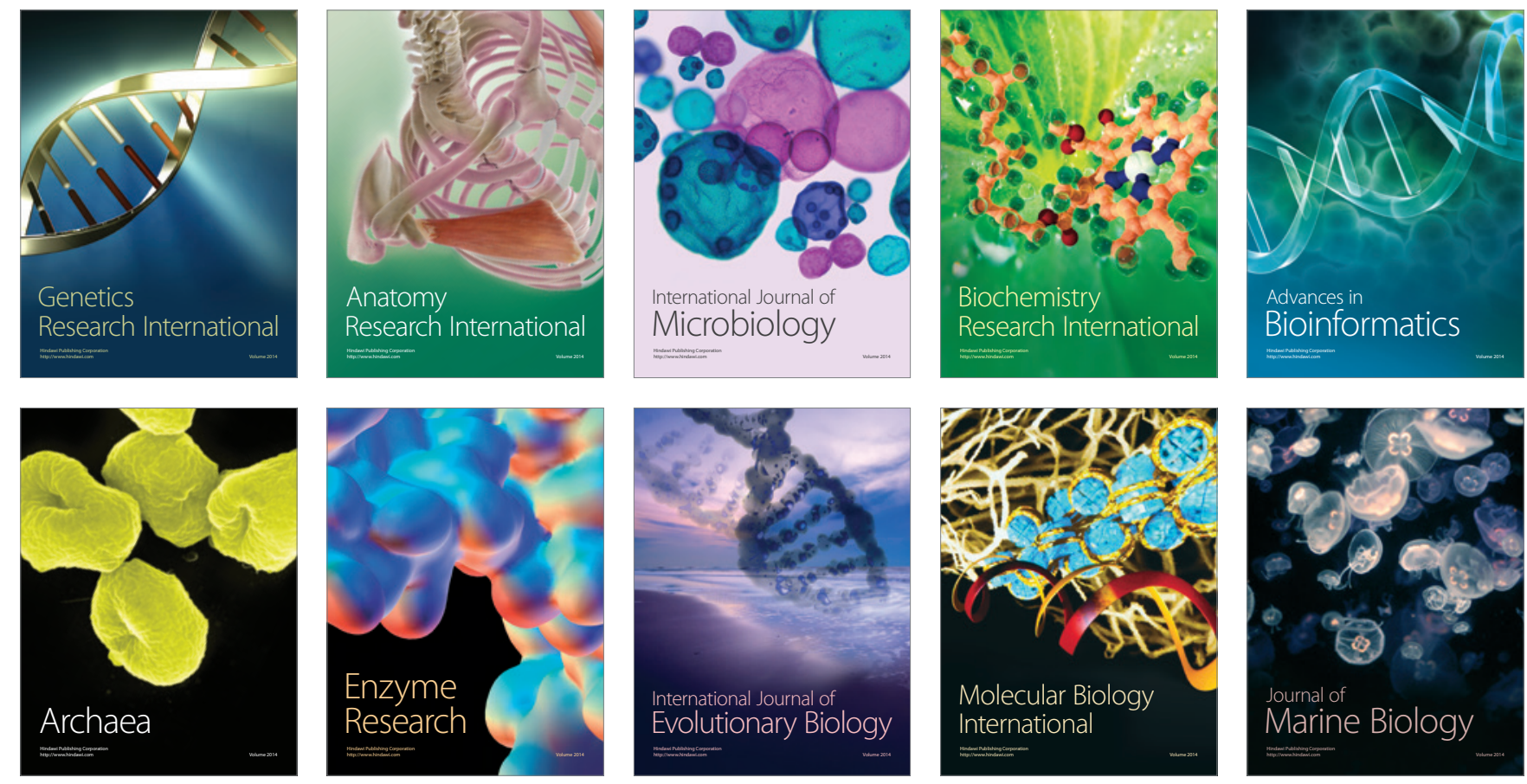